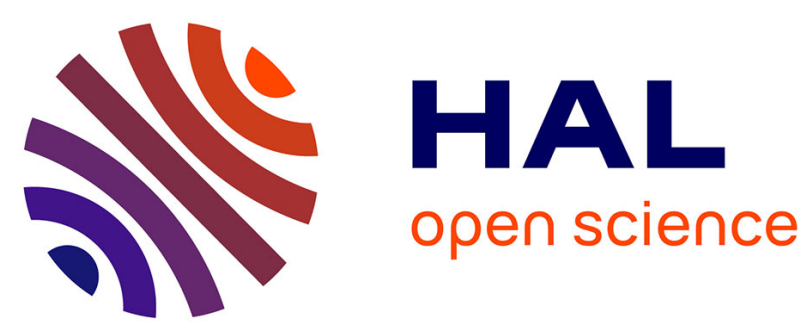

\title{
In-situ K-Ar dating on Mars based on UV-Laser ablation coupled with a LIBS-QMS system: Development, calibration and application of the KArMars instrument
}

Fanny Cattani, Pierre-Yves Gillot, Xavier Quidelleur, Anthony Hildenbrand, Jean-Claude Lefèvre, Claire Boukari, Frédéric Courtade

\section{To cite this version:}

Fanny Cattani, Pierre-Yves Gillot, Xavier Quidelleur, Anthony Hildenbrand, Jean-Claude Lefèvre, et al.. In-situ K-Ar dating on Mars based on UV-Laser ablation coupled with a LIBS-QMS system: Development, calibration and application of the KArMars instrument. Chemical Geology, 2018, 506, pp.1-16. 10.1016/j.chemgeo.2018.12.010 . hal-02067831

\section{HAL Id: hal-02067831 \\ https://hal.science/hal-02067831}

Submitted on 21 Oct 2021

HAL is a multi-disciplinary open access archive for the deposit and dissemination of scientific research documents, whether they are published or not. The documents may come from teaching and research institutions in France or abroad, or from public or private research centers.
L'archive ouverte pluridisciplinaire HAL, est destinée au dépôt et à la diffusion de documents scientifiques de niveau recherche, publiés ou non, émanant des établissements d'enseignement et de recherche français ou étrangers, des laboratoires publics ou privés.

\section{(ㄷ)(1) $\$$}

Distributed under a Creative Commons Attribution - NonCommerciall 4.0 International 


\section{In-situ K-Ar dating on Mars based on UV-Laser ablation coupled with a LIBS-QMS system: development, calibration and application of the KArMars instrument}

Fanny Cattani ${ }^{1}$, Pierre-Yves Gillot ${ }^{1}$, Xavier Quidelleur $^{1,}{ }^{*}$, Anthony Hildenbrand ${ }^{1}$, JeanClaude Lefevre ${ }^{2}$, Claire Boukari ${ }^{1}$ and Fréderic Courtade ${ }^{3}$.

${ }^{1}$ GEOPS, Univ. Paris-Sud, CNRS, Université Paris-Saclay, 91405 Orsay, France.

${ }^{2}$ Université Lyon 1, CNRS ARAR UMR 5138, Centre de datation par le radiocarbon, Villeurbanne, France.

${ }^{3}$ Centre National d'Etudes Spatiales (CNES), 18 Avenue E. Belin, 31401 Toulouse, France.

*: Corresponding author; email: xavier.quidelleur@u-psud.fr

Submitted to Chemical Geology, July, 2018.

Revised version CHEMGE-S-18-00602, December 2108.

Word counts:

Abstract: 384

Text: 9177

References: 83

Figures: 11

Tables: 7

Supp. Mat.: 2 Tables +1 Figure 


\section{Abstract}

Absolute dating is needed to check and calibrate the relative Martian chronology presently available from meteoritic crater counting. For such purpose, a new analytical system (KArMars) has been developed to experiment the feasibility of in-situ K-Ar for future landing planetary missions. It consists in a laser ablation-based system built to vaporize a reproducible volume of rock. Potassium content is measured by laser-induced breakdown spectroscopy (LIBS) and argon by quadrupole mass spectrometry (QMS). Instrument calibration, and checking of the reliability of the measurements for Martian analyses, requires terrestrial analogues. For such purpose, total chemistry, electron microprobe analyses, flame absorption spectrometry and mass spectrometry have been performed in order to qualify the stoichiometry, the mineralogy, the $\mathrm{K}$ concentration and the Ar isotopic composition from a collection of old terrestrial rocks. These new analyses coupled with published data allowed us to select mineral phases (e.g. feldspars, phlogopite, muscovite, amphibole) showing a large range of $\mathrm{K}$ content $(0.3-8.5$ wt.\%). All these mineral phases display a K-Ar age older than $300 \mathrm{Ma}$. Hence, the content of radiogenic Ar atoms per gram is within the range of Martian samples (on the order of $1 \mathrm{Ga}$ for $0.4 \mathrm{wt} . \%$ of $\mathrm{K}$ ). We have shown that the ablated mass can be precisely estimated by measurement of Ar extracted from a similar mineral of known amount of radiogenic Ar content per gram. Then, it has been possible to derive a well-defined relationship between the ablation time and the sample mass extracted from UV-laser ablations for different minerals. Using an isochron approach from multiple ablations of several samples analyzed as unknowns, we have shown that KArMars can be successfully used for dating samples with different compositions, and with ages varying by an order of magnitude from 0.3 to $3 \mathrm{Ga}$. In-situ K-Ar ages obtained here for plagioclase and amphibole crystals display uncertainties as low as about $10 \%$, and with accuracy, i.e. difference with the reference age, of only 10\%. Such results further support in-situ K-Ar dating based on QMS and LIBS 
instruments as a reliable approach to be implemented onboard Martian rovers. In case a return mission is made possible, KArMars can also be a valuable tool to select the most relevant samples for return and ensure onsite which samples are representative of most of the surface at a given landing site.

Keywords: in-situ K-Ar dating; Mars; UV laser ablation; laser-induced breakdown spectroscopy; LIBS; Quadrupole Mass Spectrometry; QMS. 


\section{Introduction}

Knowledge of the Martian chronology yet relies on relative dating based on impact craters density (e.g., Forget et al., 2006). From this approach, $80 \%$ of the Martian surface would have been formed during the first 2 billion years after initial planetary accretion. It corresponds to the Hadean and the Archean epochs on Earth, which ended around $2.5 \mathrm{Ga}$, and represent less than $2 \%$ of the present-day Earth's surface rocks. Thus, studying the surface of Mars provides insight into the conditions and early evolution of the primitive Earth.

Nevertheless, timing of Mars evolution remains poorly constrained yet, showing cratering rates and ages that can vary by a factor of four (Doran et al., 2004; Hartmann, 2005). A critical goal of the forthcoming Mars 2020 mission will be to collect a batch of samples for their possible future return to Earth and subsequent radiometric dating (Witze, 2014).

Potassium-Argon dating method is particularly suitable for such purpose. It is based on the radioactive decay of the ${ }^{40} \mathrm{~K}$, a major element universally distributed in rocks and minerals. Its daughter, ${ }^{40} \mathrm{Ar}$, is a noble gas, which accumulates as a function of time and remains in minerals of undisturbed rocks (Boynton et al., 2007; McDougall and Harrison, 1999). It is thus possible to obtain an age from combined measurements of $\mathrm{K}$ and Ar contents from a single crystal phase. This, however, requires accurate determination of the mass of the mineral on which both analyses are achieved.

Recently, several experimental settings based on spot laser analyses have been developed to investigate the feasibility of in-situ K-Ar dating (Cattani et al., 2017; Cho and Cohen, 2018; Cho et al., 2016; Cohen et al., 2014; Devismes et al., 2016; Solé, 2014). These preliminary studies have brought promising perspectives, but yet suffer important limitations. The main difficulties in performing accurate $\mathrm{K}$-Ar dating are i) to perform the total extraction and quantification of the number of ${ }^{40} \mathrm{Ar}$ atoms from a given amount of sample, and ii) to 
accurately estimate its potassium content. In order to reach these objectives, we present here KArMars, an instrumental setting based on UV-laser ablation, $\mathrm{K}$ measurement by LaserInduced Breakdown Spectroscopy (LIBS), and argon analysis by quadrupole mass spectrometer (QMS). Initiated by Devismes et al. (2016), this setting has been fully redrawn here in order to optimize the LIBS and argon isotopic measurements, and to accurately determine the mass of mineral ablated by UV-laser. For this purpose, we have qualified a set of minerals and rocks selected as Martian analog reference materials. Finally, the KArMars instrument has been validated using a set of terrestrial analogue samples dated as unknowns.

\section{In-situ K-Ar dating of Mars surface}

\subsection{Principle and applicability}

Potassium is an essential constituent of many major rock-forming minerals, such as micas, amphiboles, feldspars, clay minerals (Heier and Adams, 1964), most of which are also present on Mars (Bibring et al., 2006; Morris et al., 2016). Potassium has three natural isotopes, ${ }^{39} \mathrm{~K}$ $(93.2581 \pm 0.0029 \%),{ }^{40} \mathrm{~K}(0.0117 \pm 0.00004 \%)$ and ${ }^{41} \mathrm{~K}(6.7302 \pm 0.0029 \%)$ (Garner et al., 1975). ${ }^{40} \mathrm{~K}$ is radioactive and decays into stable ${ }^{40} \mathrm{Ca}$ and ${ }^{40} \mathrm{Ar} *$ with a half-life of $1.249 \times 10^{9}$ years (Renne et al., 2010). Therefore, the K-Ar geochronometer is suitable to date geological materials ranging in age from a thousand and less (Gillot and Cornette, 1986) to several billions of years. Potassium is an alkali metal and a solid element, while argon is a chemically inert noble gas. They occur as different phases and are easily separated during geological processes (melting, metamorphism or alteration, and diagenesis). Because Ar is an inert gas, the liquid magma degasses into the atmosphere when erupting at the surface. When the lava has solidified, the K-Ar chronometer starts to accumulate radiogenic ${ }^{40} \mathrm{Ar}\left({ }^{40} \mathrm{Ar} *\right)$. In minerals, the amount of radiogenic argon is thus a function of time and $\mathrm{K}$ content. Thus, $\mathrm{K}-\mathrm{Ar}$ measurement allows to determine the age of eruption if the system remained closed, i.e., if it 
has not experienced any significant re-heating, metamorphism or alteration. The age is calculated according to the following equation:

$\mathrm{t}=\frac{1}{\lambda} \times \ln \left[\frac{\lambda}{\lambda_{\mathrm{e}}} \times \frac{{ }^{40} \mathrm{Ar} *}{{ }^{40} \mathrm{~K}}+1\right]$

Where $\lambda=5.543 \times 10^{-10} \mathrm{yr}^{-1}$ and $\lambda_{\mathrm{e}}=0.581 \times 10^{-10} \mathrm{yr}^{-1}$ are the total decay constant of ${ }^{40} \mathrm{~K}$, and the decay constant of ${ }^{40} \mathrm{~K}$ to ${ }^{40} \mathrm{Ar} *$, respectively (Steiger and Jager, 1977). ${ }^{40} \mathrm{~K}$ is the radioactive isotope $\mathrm{K}$ [atoms] and ${ }^{40} \mathrm{Ar} *$ is the radiogenic argon produced [atoms].

The amount of ${ }^{40} \mathrm{~K}$ (in atoms) is deduced from the $\mathrm{K}$ content $\left(K_{\%}\right)$ obtained by LIBS, according to the following equation:

${ }^{40} K=\frac{K_{\%}}{100} \times 0.0001167 \times N a \times\left(\frac{m_{a}}{M_{K}}\right)$.

Where $\mathrm{Na}$ is Avogadro's number, ma is the ablated mass (in gram), and $\mathrm{M}_{\mathrm{K}}$ is the atomic weight of K (39.09834 g.mol $\left.{ }^{-1}\right)$.

${ }^{40} \mathrm{Ar} *$ is defined from the QMS ${ }^{40} \mathrm{Ar}$ measurement. Mars surface is expected to comprise mostly old rocks, which have accumulated a large amount of radiogenic argon (> 99\%). Therefore, because blanks resulting from laser ablation are very small, we can assume that all the measured argon is radiogenic, while the amount of atmospheric argon is negligible (Gillot et al., 2006).

The error on the age determination $(\Delta t)$ is calculated following:

$\Delta t=\frac{1}{\lambda}\left(1-e^{-\lambda t}\right) \sqrt{\left(\frac{\Delta\left[{ }^{40} A r\right] *}{\left[{ }^{40} A r\right] *}\right)^{2}+\left(\frac{\Delta\left[{ }^{40} K\right]}{\left[{ }^{40} K\right]}\right)^{2}}$.

Measurements of $\mathrm{K}$ and ${ }^{40} \mathrm{Ar}$ can be used for dating as long as the sample mass from which they were extracted is known. 
Using equation (2) into equation (3) yields the equation from which the derivative is calculated to determine uncertainty on age determination of this work:

$$
\Delta t=\frac{1}{\lambda}\left(1-e^{-\lambda t}\right) \sqrt{\left(\frac{\Delta\left[{ }^{40} A r^{*}\right]}{\left[{ }^{40} A r^{*}\right]}\right)^{2}+\left(\frac{\Delta\left[K_{\%}\right]}{\left[K_{\%}\right]}\right)^{2}+\left(\frac{\Delta\left[m_{a}\right]}{\left[m_{a}\right]}\right)^{2}} .
$$

KArMars age determination relies on several ablations, which could have contrasted $\mathrm{K}$ and $\mathrm{Ar}$ contents depending on the minerals hit by the laser spot. Therefore, as previously proposed (Cho et al., 2016; Cho and Cohen, 2018; Cohen et al., 2014; Solé, 2014), the best way to calculate the age of a given sample is to rely on the isochron approach. Indeed, spot-by-spot UV laser ablations provide a sufficient range of $\mathrm{K}$ contents to obtain relatively well-defined isochron slopes. Then, in order to obtain a precise age from a single sample, we use the following equation:

${ }^{40} A r={ }^{40} A r_{i}+\left(\frac{\lambda_{e}}{\lambda}\right){ }^{40} K\left(e^{\lambda t}-1\right)$,

where ${ }^{40} \mathrm{Ar}_{\mathrm{i}}$ represents the number of ${ }^{40} \mathrm{Ar}$ atoms of sample that where not formed by decay of ${ }^{40} \mathrm{~K}$ since closure of the rock or mineral (i.e., the possible excess of ${ }^{40} \mathrm{Ar}$ described by Bogard and Park, 2008). Nevertheless, K-bearing phases coexisting in the same sample are supposed cogenetic and thus may have comparable ${ }^{40} \mathrm{Ar}_{\mathrm{i}}$. Moreover, such rapidly-cooled coexisting phases have the same K-Ar age (Faure, 1986). Therefore, the equation 5 represents a family of straight lines in coordinates of ${ }^{40} \mathrm{Ar}$ and ${ }^{40} \mathrm{~K}$, where the intercept on the y axis is $b={ }^{40}{ }^{40} r_{i}$ and the slope is $m=\left(\frac{\lambda_{e}}{\lambda}\right)\left(e^{\lambda t}-1\right)$. The slope $m$ of this straight line is a function of the age, given by:

$t=\frac{1}{\lambda} \ln \left[m\left(\frac{\lambda}{\lambda_{e}}\right)+1\right]$. 
Hence, the isochron approach allows to reduce the total uncertainty applied on spot-by-spot ages (equation 6) by considering only uncertainty on the slope of the isochron line determined by least squares fitting (Mahon, 1996)

\subsection{Previous attempts}

Although different radiometric techniques have been considered for in-situ dating planetary surfaces (Anderson et al., 2015; Morgan et al., 2017; Riedo et al., 2013), the K-Ar technique appears as the most suitable to date rocks from the Martian volcanic surface (Boynton et al., 2007; Cho et al., 2016; Cho and Cohen, 2018; Cohen et al., 2014; Devismes et al., 2016; Farley et al., 2013; McDougall and Harrison, 1999; Solé, 2014; Talboys et al., 2009).

During MSL mission, a first in-situ dating experiment was conducted on a sedimentary rock sampled at the surface of Mars. A mudstone, from the floor of the Gale crater, was cored and degassed under high vacuum $\left(900^{\circ} \mathrm{C}, 25\right.$ minutes) (Mahaffy et al., 2012) in order to extract and analyze argon using a QMS into Sample Analysis at Mars instrument (SAM) instrument (Mahaffy et al., 2012). The whole rock $\mathrm{K}_{2} \mathrm{O}$ content was estimated by identification of the different minerals (feldspars, glass, clays, etc.) and their relative abundance by CheMin (Xray diffraction; Vaniman et al., 2014) which allows to roughly estimate a whole-rock mean K\% content (Farley et al., 2014). From the total Ar measurement, the authors estimated a KAr age of $4.21 \pm 0.35 \mathrm{Ga}$, which suggests that $\mathrm{K}$-Ar dating is actually possible on Mars (Farley et al., 2014). However, because it was obtained from a sedimentary rock containing a mixture of detrital and authigenic minerals, such value cannot be unambiguously interpreted as the age of the rock formation.

During the last ten years, analytical systems including a laser have been developed for in-situ $\mathrm{K} /$ Ar dating. Laser ablation appears as the most suitable approach for creating a plasma in order to determine K content and to extract Ar simultaneously (Cattani et al., 2017; Cho et al., 
2016; Cho and Cohen, 2018; Cohen et al., 2014; Devismes et al., 2016; Solé, 2014). For example, to extract $99 \%$ of ${ }^{40} \mathrm{Ar}$ from a shergottite feldspar, a furnace has to be maintained between 900 and $1000^{\circ} \mathrm{C}$ for 3 to $30 \mathrm{~h}$ (Bogard, 2009). The same result can be obtained by using laser ablation, which requires much less energy.

Previous laser ablation-based systems (Cho et al., 2016; Cohen et al., 2014; Devismes et al., 2016; Solé, 2014) display various instrumental designs and analytical methods, but most are based on: i) the laser induced breakdown spectroscopy technique, using an optic spectrometer with a resolution high enough to observe both emission lines of $\mathrm{K}(766.49$ and $769.89 \mathrm{~nm})$; ii) a QMS to analyze the abundance and composition of Ar released by laser ablation; and iii) an ablated mass determination obtained generally by the profilometry technique. These studies present K-Ar ages, obtained from K-rich phases, with relative uncertainty between 5 and $25 \%$, depending on the sample age and $\mathrm{K}$ content of the mineral phase analyzed.

\section{Methods}

\subsection{New instrument development and calibration}

Calibration of the LIBS and QMS, as well as improved quantification of the ablated mass are here investigated through the development of a collection of reference samples with chemistry and ${ }^{40} \mathrm{Ar} *$ yields determined independently.

\subsubsection{UV laser ablation and LIBS method}

The laser Induced Breakdown Spectroscopy (LIBS) technique allows a spectral analysis of the plasma light through the characteristic emission wavelength of various major elements present in the sample, such as $\mathrm{O}, \mathrm{Na}, \mathrm{Mg}, \mathrm{Al}, \mathrm{Si}, \mathrm{K}, \mathrm{Ca}$, and $\mathrm{Fe}$. In order to determine elemental compositions from LIBS spectra, two techniques are applied: univariate analysis and partial least squares technique (PLS). The univariate technique correlates, for each 
element, the LIBS signal to a known concentration using calibration curves based on standards analyses (Fabre et al., 2014). This technique needs to preprocess the signal before analysis in order to control parameters that affect the precision and accuracy of measurement such as laser fluctuation, atmosphere above sample, chemical and physical matrix effects, self-absorption, etc. (Cremers and Radziemski, 2006). The signal is then normalized by the total intensity, the total area, or using an internal standard (Aragon et al., 1999; Body and Chadwick, 2001; Fabre et al., 2014; Mosier-Boss et al., 2002; Sallé et al., 2006; Tucker, 2009). The second technique, the PLS technique, commonly used for LIBS, is a multivariate analysis method (Clegg et al., 2009; Tucker et al., 2010). It overcomes chemical matrix effects to a certain extent (Guezenoc et al., 2017), but needs an accurate and complete standard database. The LIBS technique has been used for 30 years for elementary analyses (Coche et al., 1989; Cremers and Radziemski, 2006, 1983), and the ChemCam experiment represents the first use of the LIBS technique on another planet (Maurice et al., 2012; Perez et al., 2011; Wiens et al., 2012). The main advantage of LIBS for this study is that it can be performed on a whole-rock or chip sample after slight polishing to flatten the sample.

Fig. 1 presents a schematic diagram of KArMars system. A pulsed UV laser is focused on sample and produce plasma in a vacuum chamber. We use a Nd:YAG laser (Spectra Physics GCR-130) with a quadrupled wavelength of $266 \mathrm{~nm}$ in order to perform laser ablation by mechanical impact, while thermal effects around the laser spot remain limited (Cabalin and Laserna, 1998; Cho et al., 2013).

The generated laser pulses have a duration of $14 \mathrm{~ns}$ and a frequency of $10 \mathrm{~Hz}$, and power is stabilized at $0.2 \mathrm{~W}$ to better than $5 \%$ for 300 pulses. The irradiance on the sample is about 2 $\mathrm{GW} / \mathrm{cm}^{2}$ and the laser spot diameter about $300 \mu \mathrm{m}$. A pyroelectric laser energy sensor controls the UV laser power during ablation, and a laser shutter controls its duration. In order to change the direction of the laser beam, a dielectric glass lens is used to refract $60.5 \%$ of the 
UV laser towards a spherical lens that focuses the beam on the sample surface underneath. The remaining $39.5 \%$ un-deviated UV laser is focused on the pyroelectric laser energy sensor surface, which allows monitoring laser power and steadiness. The sample is kept under ultrahigh vacuum (maintained by a turbo-molecular pump at around $10^{-8} \mathrm{mbar}$ ) by placing it under a fused silica glass window placed $17 \mathrm{~cm}$ above the surface of the sample. Such distance minimizes opacification of the window by sublimated particles from the plasma and allows us to use high laser intensity without damaging the window.

An Ocean Optics HR2000+ spectrometer is used in KArMars for LIBS analyses of the minerals chemistry. It has a spectral range from 395 to $830 \mathrm{~nm}$ with 2048 pixels, which makes possible the accurate determination of major element concentrations, including $\mathrm{K}$, and a resolution of $0.25 \mathrm{~nm}$, which helps to precisely detect of the two close emission lines of $\mathrm{K}$ at 766.49 and $769.89 \mathrm{~nm}$. The optical signal emitted from the laser-produced plasma, with a light emission diameter lower than $2 \mathrm{~mm}$, passes through $1 \mathrm{~mm}$ wide optical fiber, and through a $25 \mu \mathrm{m}$ wide slit. It is located nearly horizontally above the plasma at a short distance $(<5 \mathrm{~cm})$, in order to improve recording of most plasma light via the optical fiber. Due to the low intensity of the light signal released from the plasma under ultra-high vacuum (Effenberger and Scott, 2010), and to fluctuations in laser power (of about 5\%), each spectrum is calculated as the average of 10 spectra obtained from an integration time of 500 ms. As each plasma fades in less than $0.1 \mathrm{~ms}$ (Cremers and Radziemski, 2006), and since the laser is operated at $10 \mathrm{~Hz}$ frequency, this corresponds to the total light emitted from 5 different plasmas. This allows us to obtain a mean spectrum with a signal/noise ratio optimized each 5 seconds, therefore corresponding to the average of 50 different plasmas (produced from 50 laser pulses). Taking into account that the total ablation time is between 15 and 60 seconds, depending on Ar content released (the lower the Ar content, the longer the ablation needed for a good QMS measurement), LIBS data are thus obtained from a total of 
150-600 laser pulses performed at the same location. It can be viewed as performing a depth profile, about $300 \mu \mathrm{m}$ wide and $<500 \mu \mathrm{m}$ deep, which, therefore, limits this approach to relatively thick minerals. In addition, as the plasma intensity varies during ablation, most likely due to changes in surface conditions between the top and the bottom of the crater as laser ablation excavates the sample (Cho et al., 2015), the signal of each element is calculated as its integrated peak area normalized by the whole spectrum integrated emission intensity (Cohen et al., 2014; Dyar et al., 2011; Fabre et al., 2014, 2011; Stipe et al., 2012; Wiens et al., 2013). The LIBS used in KArMars allows simultaneous measurements of several peaks of interests, with characteristic wavelength as determined by NIST database for K (766.49 $\mathrm{nm}$ and $769.89 \mathrm{~nm}), \mathrm{Ca}(422.79 \mathrm{~nm}), \mathrm{Mg}(518.51 \mathrm{~nm}), \mathrm{Si}(505.74 \mathrm{~nm}), \mathrm{Na}(589.16 \mathrm{~nm})$ and $\mathrm{O}$ (777.41 nm). Fe was not determined here because the analyzed spectral range does not allow. In this study, we focused more specifically on the $\mathrm{K}$ doublet to obtain an accurate determination of $\mathrm{K}$ content for sake of dating. However, the other elements are also determined to identify the nature of the ablated mineral, with special emphasis on $\mathrm{Mg}$ and $\mathrm{Fe}$ contents determinations. Indeed, the strongest $\mathrm{K}$ line appears at $766.49 \mathrm{~nm}$, but secondary $\mathrm{Mg}$ I and Fe I emissions are present at $765.76 \mathrm{~nm}$ and $767.61 \mathrm{~nm}$ respectively. Unfortunately, the optic spectrometer resolution $(0.25 \mathrm{~nm})$ is not sufficient to separate these peaks (Cho et al., 2015). Therefore, in order to avoid overestimation of the $K$ content, the second strongest $K$ emission line at $769.89 \mathrm{~nm}$ is used instead for samples with high $\mathrm{Mg}$ content.

In this study, we define the most suitable parameters for $\mathrm{K}$ content determinations using LIBS, in order to perform accurate in-situ K-Ar dating using a UV laser and under ultravacuum with reduced matrix and self-absorption effects. For that, we have used reference samples presented below, with characteristics close to the Martian rocks and known ages, and international standards (JA-3, JB-2, SRM278, and AGV-2) with known chemistry. 


\subsubsection{Quadrupole Mass Spectrometry (QMS)}

Before SAM instrument can be used on Mars for absolute dating, it requires a precise calibration in order to determine the correlation between the measured intensity and the number of ${ }^{40} \mathrm{Ar}$ atoms. Laser ablation provides only a very low amount of ${ }^{40} \mathrm{Ar} *$, which directly affects the uncertainty on ${ }^{40} \mathrm{Ar} *$ measurement. Therefore, using reference samples, we have first investigated the limits of the QMS and the optimal ablation parameters to be used. This allowed us to define the linearity, the reproducibility, the accuracy and the relationship between measured intensity and number of atoms introduced of our QMS. We have used here a SXP Elite VG QMS upgraded from Rouchon et al. (2008) and Devismes et al. (2016). The QMS performed electron-impact ionization using a thoriated iridium filament source. The analyzer (VG $\mathrm{AN}-9 \mathrm{~N})$ is composed of a rod system of four 12-mm diameter molybdenum electrodes, and the source conditions are controlled by the original VG SXP-Elite electronics: trap-current control of $0.3 \mathrm{~mA}$ (regulates the electron production) and electron energy setting of $47 \mathrm{eV}$ (minimizing double ionization effects). Ion detection is achieved by an electron multiplier (EM under high-voltage of $1300 \mathrm{~V}$ ) for weak signals, while a faraday cup is used for stronger signals. The output of the EM is measured by a Keithley 6514 picoammeter with an internal noise below $10^{-16} \mathrm{~A}$. The QMS volume is about $1 \mathrm{~L}$. The default VG radiofrequency generator ranged in mass from 0 to $50 \mathrm{amu}$. We adjusted it to be constrained in a flat region between masses 36 and 40 . The $\mathrm{m} / \Delta \mathrm{m}$ value is 400 at a mass of 40 (resolution at $0.1 \mathrm{amu}$ ), which is sufficient as ${ }^{40} \mathrm{Ar}$ is the only gas present with a mass of $40 \mathrm{amu}$. The chamber is isolated during ablation and the released gas is purified by a SAES MP-10 Zr-Al getter operating at $400^{\circ} \mathrm{C}$ before introduction in the QMS. The latter is calibrated by analysis of known atmospheric argon aliquots (doses). Indeed, a reproducible amount of atmospheric argon (calibrated dose, CD) is pipetted to convert the electronic intensity into number of atoms, and hence to calibrate the QMS detectors. For the faraday cup, we use a large CD 
(LCD) and a small CD (SCD) for the electron multiplier. From volumetric calculations and calibration by reference minerals (selected and characterized in this study, such as phlogopite 15-yates-1-bio, muscovite 15-limou-1-musc and amphibolite AMP3.8), and available standard minerals GLO (Odin and et al., 1982) and LP6 (Baksi et al., 1996), we have determined that a LCD contains $3.05 \pm 0.04 \times 10^{14}$ atoms of ${ }^{40} \mathrm{Ar}$ (Fig. 2) and $1.13 \pm 0.01 \mathrm{x}$ $10^{12}$ atoms of ${ }^{36} \mathrm{Ar}$, which gives a ${ }^{40} \mathrm{Ar} /{ }^{36} \mathrm{Ar}$ ratio of $271 \pm 2$. The difference to the reference value of ${ }^{40} \mathrm{Ar} /{ }^{36} \mathrm{Ar}$ atm $=295.5$ (Steiger and Jager, 1977) is due to the mass discrimination in the ion source, in the analyzer and the ion detection system, all contributing to the mass dependence of the QMS isotopic ratios (Rouchon et al., 2008; Schneider et al., 2009). Since the tank used for SCD was filled from 1 pipette of LCD, volumetric calculations allowed us to determine that one SCD contains $4.42 \pm 0.05 \times 10^{10}$ atoms of ${ }^{40} \mathrm{Ar}$ and $1.63 \pm 0.02 \times 10^{8}$ atoms of ${ }^{36} \mathrm{Ar}$.

Mass spectrometer signal evolution during analysis is function of signal height, which may promote either implantation on the QMS, or release of adsorbed argon from QMS surface during sample measurement (Fig. 3). In order to account for these phenomena, a $2^{\text {nd }}$ order polynomial regression is performed to obtain the initial value (at $t=t_{0}$ ), when the signal is equilibrated into the QMS after isolation from the rest of the line. Linearity and reproducibility of QMS measurements have been tested using increment and decrement of several aliquots of SCD. In addition, comparison between measurement of successive decrements and theoretical data (e.g., Coulié et al., 2004), calculated from a 1.31 volumetric ratio, highlighted the extended linearity response of the QMS for signals between 0.2 and 71 $\mathrm{x} 10^{-11} \mathrm{~A}$.

Before gas introduction and measurement, the line is heated for a few days at about $90^{\circ} \mathrm{C}$ while pumping, until the pressure decreases below $10^{-8} \mathrm{mbar}$, in order to achieve low blanks. 
Such long pumping duration is mainly due to the use of chips samples with natural porosity, which have trapped a large amount of atmospheric gas adsorbed at the surface of the rock. The analysis of argon is achieved in 3 steps (Fig. 1): i) Measurement of line blanks with laser off. ii) Measurement of the ablation signal with laser power set at $0.2 \mathrm{~W}$ and the cell valve closed during ablation, which lasts between 5 and 90 seconds, depending on the mineral analyzed. After 90 seconds, the cell valve is open for 210 seconds of gas purification. Then, argon is expanded in the QMS until pressure is equilibrated (between 20 and 30 seconds), and the QMS valve is closed for measurement of masse 40 in static mode during about 180 seconds. iii) Measurement of a $\mathrm{CD}$ aliquot in the same volume and conditions than used for analysis of gas sample in order to quantify the number of ${ }^{40} \mathrm{Ar}$ atoms released during ablation.

\subsubsection{Ablated mass}

The ablated mass was first estimated by volume measurements performed by the profilometry technique using a Sensofar 3D Optical Profilers at CNES (Toulouse, France), and the estimated density of the ablated mineral. The craters resulting from ablation were inspected with a scanning electron microscopy (SEM) to characterize their aspect. In addition, another approach has been systematically developed here. It consists in the measurement by QMS of

${ }^{40} \mathrm{Ar}$ extracted by ablation of a mineral with known amount of radiogenic ${ }^{40} \mathrm{Ar}$ per gram as deduced from independent $\mathrm{K} / \mathrm{Ar}$ and ${ }^{40} \mathrm{Ar} /{ }^{39} \mathrm{Ar}$ measurements on mineral separates of the same rock. For such purpose, we developed a dataset of new reference minerals. The use of such a variety of common minerals allows assessing the possible variable response of each of type of mineral to ablation, and to derive a correlation between ablated mass and ablation time (ablation by 10 laser pulses per second). 


\subsection{Development of new reference materials}

Observation of thin sections, whole-rock chemistry and Electron microprobe analyses (WDS) were performed in order to qualify the mineralogy and the stoichiometry of a set of old terrestrial rocks with various textures. A careful mineralogical separation was performed and the $\mathrm{K}$ content was measured by flame absorption spectrometry, and Ar was measured with a mass spectrometer following the K-Ar method (Gillot et al., 2006). In addition, ${ }^{40} \mathrm{Ar} /{ }^{39} \mathrm{Ar}$ dating was also performed for some samples.

\subsubsection{Analogy to Martian samples}

The Spirit landing (McSween et al., 2004), and the Mars Odyssey Thermal Emission Imaging System (THEMIS; Christensen et al., 2005), have identified the occurrence of a wide diversity of igneous materials on Mars. The Alpha Particle X-ray Spectrometer chemical analyses of rocks from Gusev crater are consistent with picritic basalts containing normative olivine, pyroxenes, plagioclase, and accessory Fe-Ti oxides (McSween et al., 2004). Quartzbearing granitoid rocks have also been discovered by THEMIS, revealing that high degree of differentiation has occurred. Currently, the Mars Science Laboratory (MSL) rover Curiosity explores sedimentary rocks within the Gale crater. Some instruments operating on Curiosity, like the Chemistry Camera (ChemCam) or the Chemistry and Mineralogy X-ray diffraction (CheMin), performed textural and compositional analyses. They identified a variety of textures including porphyritic samples with dark grains (likely pyroxene megacrysts) in a fine-grained groundmass containing plagioclase needles, and coarse-grained rocks showing equigranular texture with millimeter size crystals of plagioclases and $\mathrm{Fe}$-Ti oxides (Cousin et al., 2017; Sautter et al., 2014). Coarse gravels surrounding Gale crater are dominated by feldspathic (andesine-bytownite) clasts. These observations document a relatively wide magmatic diversity at Gale crater, and describe the first fragments of feldspar-rich lithologies (possibly an anorthosite), that may originate from ancient crust transported from the crater rim 
and now forming float rocks, coarse gravel, or conglomerate clasts (Palucis et al., 2013; Sautter et al., 2014; Williams et al., 2013). These studies highlight the ubiquitous presence of feldspars-rich (K-bearing phases) of the Martian crust. Furthermore, lithium, strontium, rubidium, and/or barium enrichments, mainly related to the presence of alkali materials (mica, feldspar, and K-phyllosilicate) due to evolved, or low partial melting, magmatic systems have been reported from Curiosity rover data (Payré et al., 2017). Therefore, in order to define a set of terrestrial analogues to Martian rocks, basaltic, feldspar-rich rocks and micas have been selected in the present study.

Homogeneous mono-crystal samples with well-established stoichiometry were selected to qualify LIBS measurements (Table 1). There are 2 mono-crystals investigated by previous studies: i) a dark mica, 15-yates-1-bio, sampled from a pegmatite at Yates mine, Otter Lake (Quebec, Canada) and dated at $913 \pm 7$ Ma with the Lu-Hf method on apatites (Barfod et al., 2005); ii) a muscovite, 15-limou-1-musc, sampled from an intrusive pegmatite in Massif Central (Limousin, France) and dated at $309 \pm 5 \mathrm{Ma}$ with the U-Pb and ${ }^{40} \mathrm{Ar} /{ }^{39} \mathrm{Ar}$ methods applied on lepidolites and oxides (columbites and tantalites) (Cheilletz et al., 1992; Melleton et al., 2011).

Additionally, massive samples composed of different minerals and various textures (Table 1) were selected to further improve LIBS determination and properly account for different effects (e.g. matrix effect, self-absorption, analyzes of several minerals simultaneously). They will also be used to determine QMS detection limits on rocks with similar ${ }^{40} \mathrm{Ar}$ yield than Martian basalts. The rocks samples are: i) an amphibolite composed of amphiboles and plagioclases, AMP3.8, from Nuvvuagittuq complex (Canada). The zircons have been dated at $2693 \pm 3$ Ma by the U-Pb method (David et al., 2009); ii) an enderbite (ADB) composed of quartz, plagioclases, pyroxenes, biotites and amphiboles, from Churchill province (Canada). The zircons have been dated at $1860 \pm 15$ Ga by the U-Pb method (Davis et al., 2018); iii) a 
dolerite from Viluy Traps principally composed of clinopyroxenes and plagioclases (30-01), sampled along the Viluy river (Siberian platform, Russia). The plagioclases from this sample show a K content of 0.202 wt. $\%$ and are dated at $370 \pm 5$ Ma using the K-Ar Cassignol-Gillot technique (Courtillot et al., 2010). ${ }^{40} \mathrm{Ar} /{ }^{39} \mathrm{Ar}$ data obtained on the same mineral separates yield similar results, with plateau ages at $370 \pm 2 \mathrm{Ma}$ (Courtillot et al., 2010).

\subsubsection{Total chemistry (stoichiometry and composition)}

Major elements analyses of metagabbroic minerals have been performed with a Cameca SX100 electron probe microanalyzer (EPMA) at the Laboratoire Magmas et Volcans (Clermont-Ferrand, France). The primary acceleration voltage was $15 \mathrm{kV}$, a $15 \mathrm{nA}$ beam current and $5 \mu \mathrm{m}$ beam diameter was used for all mineral analyses. The counting time was 10 s for all elements. The detection limits of this procedure are between 400 and 900 ppm for K. Quantitative analyses were conducted for multiple spots on multiple grains to assess the variation in $\mathrm{K}$ contents within each sample.

The chemical composition of whole-rock and K-bearing phases (phlogopite, muscovite, amphiboles and feldspars) was analyzed by inductively coupled plasma optical emission spectrometry (ICP-OES) for major elements, and inductively coupled plasma-mass spectrometry (ICP-MS) for trace elements, at the Centre de Recherches Pétrographiques et Géochimiques - Service d'Analyse des Roches et des Minéraux (CRPG-SARM) facility (Nancy, France). Furthermore, total volatiles were analyzed by loss on ignition (LOI) using the weight difference after ignition at $1000^{\circ} \mathrm{C}$; obtained data likely represent a combination of structural $\mathrm{H}_{2} \mathrm{O}$ and $\mathrm{CO}_{2}$ in the minerals along with some minor organics.

\subsubsection{New K-Ar ages on separated minerals}

In order to further qualify our reference samples, new $\mathrm{K}$-Ar analyses on separated mineralogical phases were performed in the GEOPS geochronology laboratory (Universite 
Paris-Sud, France). Following thin section examination, careful separations were performed using heavy liquids in a narrow density interval in order to select the main mineral phases and obtain pure and homogeneous mineral preparation.

The determination of $\mathrm{K}$ was carried out by flame absorption spectrometry and was compared with reference values for MDO-G (Gillot et al., 1992) and BCR-2 (United States Geological Survey; USGS, Jochum et al., 2005) standards. For each reference material, an aliquot of minerals (typically between 5 and $30 \mathrm{mg}$ ) was used. This technique is suitable to measure the whole range of $\mathrm{K}$ compositions in rocks and minerals, from less than $0.1 \mathrm{wt} \%$ to up to 15 wt.\%, with a relative uncertainty of $1 \%$ in all cases (Gillot et al., 2006).

Then, using another aliquot of the separated minerals, argon was measured with a mass spectrometer similar to the one described by (Gillot and Cornette, 1986). The air aliquot used to calibrate the ${ }^{40} \mathrm{Ar}$ measurements is calibrated by routine measurements of the interlaboratory standard HD-B1 (Fuhrmann et al., 1987). This technique is suitable for dating into the last millennia (Gillot et al., 2006; Quidelleur et al., 2001), as well as into the preCambrian (Sagna et al., 2017). Note that for old samples determination, the total relative age uncertainty is $1.4 \%$ and is calculated as the quadratic sum of the $1 \%$ uncertainties attached to both the $\mathrm{K}$ content determination and the ${ }^{40} \mathrm{Ar}$ calibration, the radiogenic argon content uncertainty being negligible.

Both $\mathrm{K}$ and Ar data were duplicated for all samples. Uncertainties are given at the $1 \sigma$ level, and decay constants and $\mathrm{K}$ isotopic ratios of (Garner et al., 1975) have been used throughout this study. 


\section{Results}

\subsection{Whole-rock geochemistry of our new reference materials}

Analyses of AMP3.8 and Viluy basalts show a LOI lower than 1 wt.\%, indicating no significant alteration. Analyses of 15-yates-1-bio (dark mica) and 15-limou-1-musc (muscovite) show a range of LOI between 3 and $6 \mathrm{wt} . \%$, which reflects the high water content of these minerals.

15-yates-1-bio (dark mica) analyses (by ICP-OES and EPMA are comparable within the range of accuracy and yielded value of $19.2 \mathrm{Si}$ wt.\%, $0.3 \mathrm{Ti}$ wt.\%, 5.5 Al wt.\%, 8.0 Fe wt.\%, 12.2 $\mathrm{Mg}$ wt.\%, $0.1 \mathrm{Na}$ wt.\% and $8.5 \mathrm{~K}$ wt.\%. This shows a major-elements composition of phlogopite with a structural formula of $\mathrm{K}\left(\mathrm{Mg}_{2.5} \mathrm{Fe}_{0.5}\right)\left(\mathrm{AlSi}_{3}\right) \mathrm{O}_{10}(\mathrm{OH})_{2}$ (Supp. Table 1; Table 2).

15-limou-1-musc (white mica) results by ICP-OES and EPM are also comparable within the range of accuracy with value of $21.1 \mathrm{Si}$ wt.\%, $0.3 \mathrm{Ti}$ wt.\%, $16.6 \mathrm{Al}$ wt.\%, $3.1 \mathrm{Fe}$ wt.\%, 0.6 Mg wt. $\%, 0.4 \mathrm{Na}$ wt.\% and $8.6 \mathrm{~K}$ wt.\%. This shows a major-elements composition of muscovite with a structural formula of $\mathrm{KAl}_{2}\left(\mathrm{AlSi}_{3}\right) \mathrm{O}_{10}(\mathrm{OH})_{2}$ (Supp. Table 1; Table 2).

AMP3.8: Both amphibole and plagioclase minerals, and whole-rock of AMP3.8 were analyzed. Results obtained by ICP-OES and EPMA on amphiboles are similar, with $22.0 \mathrm{Si}$ wt.\%, 0.5 Ti wt.\%, 4.5 Al wt.\%, 11.7 Fe wt.\%, 7.3 Mg wt.\%, 0.3 Mn wt.\%, 7.9 Ca wt.\%, 0.7 $\mathrm{Na}$ wt.\% and $0.35 \mathrm{~K}$ wt.\%. This allows to determine the structural formula of $\mathrm{Ca}_{2}\left[\mathrm{Mg}_{4}\left(\mathrm{Al}, \mathrm{Fe}^{3+}\right)\right] \mathrm{Si}_{7} \mathrm{AlO}_{22}(\mathrm{OH})_{2}$, which corresponds to a magnesio-hornblende. Plagioclase crystals analyzed by EPMA show a composition between bytownite and labradorite with 23.1-24.0 Si wt.\%, 17.0-16.3 Al wt.\%, 11.0-9.8 Ca wt.\%, 2.2-2.8 Na wt.\% and 0.04-0.05 K wt.\%. Whole-rock was measured by ICP-OES and shows a composition between amphibole 
and plagioclase phases, with 22.9 Si wt.\%, 0.3 Ti wt.\%, 8.6 Al wt.\%, 7.6 Fe wt.\%, 4.8 Mg wt.\%, 0.2 Mn wt.\%, 8.5 Ca wt.\%, $1.3 \mathrm{Na}$ wt.\% and 0.39 K wt.\% (Supp. Table 1; Table 2).

K contents of K-bearing minerals (phlogopite, muscovite, feldspar and amphibole) obtained by EPMA and ICP-OES are given in Table 2. Overall the dataset shows a large range of values, between $0.04 \pm 0.02$ wt. $\%$ (plagioclase from AMP3.8) and $8.74 \pm 0.42$ wt. $\%$ (muscovite from 15-limou-1-musc) for EPMA, and between $0.35 \pm 0.09$ wt.\% (amphibole from AMP3.8) and $8.49 \pm 0.42$ wt.\% (muscovite from 15-limou-1-musc) for ICP-OES.

EPMA data highlight the large variety of feldspars present in our dataset, ranging from labradorite and bytownite composition (Table 2). It can be noted that bytownite is expected in rocks from the Martian crust (Sautter et al., 2014).

\subsection{K-Ar ages of our new reference materials}

The six new $\mathrm{K}$-Ar ages obtained here (Table 3) range from $310.2 \pm 4.4$ (15-limou-1-musc) to $2649 \pm 38 \mathrm{Ma}$ (amphibole of AMP3.8). Both K and Ar analyses were duplicated for each sample and are consistent at the $1 \sigma$ level. The K contents, obtained by spectrophotometry, range between 0.29 and 8.49 wt.\% (Table 3). The results obtained using both ICP-OES and spectrophotometry appear in fairly good agreement, but flame spectrophotometry is more accurate and has a relative uncertainty of only $1 \%$.

Fig. 4 shows $\mathrm{K}$ content plotted as a function of ${ }^{40} \mathrm{Ar}$ atoms number (in atoms per gram) derived from these analyses. Sample 15 -limou-1-musc presents a similar ${ }^{40} \mathrm{Ar}$ content as the one expected for Martian basalts, while Viluy Traps basalt (30-01) show a K content comparable to minerals observed on Mars. Both amphibole and plagioclase minerals from AMP3.8 sample (amphibolite) and plagioclase minerals from ADB sample (enderbite) have comparable $\mathrm{K}$ and Ar contents than most Martian surface rocks. On the other hand, sample 15-yates-1-bio (dark mica) is outside the Martian range, but this phlogopite can be used to 
define the quantification and detection limits of the different devices, which compose KArMars.

\subsection{K-Ar measurements performed with KArMars for in-situ dating}

\subsubsection{LIBS K data}

In order to optimize LIBS calibration for $\mathrm{K}$ determinations, 4 basaltic and andesitic standard glasses (JA-3, JB-2, SRM278, and AGV-2 powders, melted into glasses at $1100^{\circ} \mathrm{C}$ under a pressure of $600 \mathrm{~kg} / \mathrm{cm}^{2}$ in order to obtain homogenous material), and each of our new reference minerals (plagioclase and amphibole from AMP3.8, and dark mica from 15-yates-1bio) were selected. JA-3 and JB-2 were characterized by the National Institute of Advanced Industrial Sciences and Technology (AIST), and AGV-2 and SRM278 by the USGS. Fig. 5 shows the calibration curves obtained for each of the potassium peak (766 nm and $770 \mathrm{~nm})$. Calibration curves were fitted with a power law with the following parameters:

$N_{766}=0.0431 \times C^{0.6439}$, and:

$N_{770}=0.0204 \times C^{0.6761}$,

where $\mathrm{N}_{766}$ and $\mathrm{N}_{770}$ are the peak areas (determined by a trapezoidal-law applied with the National Instrument LabView software) at $766 \mathrm{~nm}$ and $770 \mathrm{~nm}$, respectively, normalized by the total spectrum intensity, and $\mathrm{C}$ is the known $\mathrm{K}$ content (in wt.\%) (Fig. 5 and Table 4). Note that, in order to obtain K content from LIBS analysis, we have selected the emission line at $766 \mathrm{~nm}$ when there is no interference line. In such case, a simple observation of the spectrum helps to define which kind of emission line must be selected.

The overall non-linear trend (Fig. 5), and the increasing uncertainty, can be explained by i) the self-absorption, that is considered to be fostered when the fundamental level is involved in the transition, which is the case of the two potassium lines considered in this study (Cho et al., 2015; Cho and Cohen, 2018; Cremers and Radziemski, 2006; Guezenoc et al., 2017); ii) the 
decreasing luminosity of the plasma hidden by the walls of the created crater as ablation is going on (for long ablation time, which depends on Ar content); and iii) the matrix effects, which include changes in chemical composition (e.g. mineral zonation) and in physical properties (e.g. hardness, porosity, or grain size; Guezenoc et al., 2017). Furthermore, in Narich samples (such as SRM278; Table 4) chemical matrix effect can be observed when ablation time increases. Indeed, the presence of dissolved $\mathrm{NaCl}$ that causes an increase of the plasma temperature and the excited atoms, leading to a stronger emission signal of the analytes and results show that $\mathrm{K}$ emission lines are dependent on $\mathrm{NaCl}$ concentration (Cremers and Knight, 2000; Goueguel et al., 2014). The limit of detection (LOD) and the limit of quantification (LOQ) of $\mathrm{K}$ determinations are derived from the calibration curves. To avoid the self-absorption, we selected only the lowest concentration (between 0.29-3.45 wt.\%) and thus obtained a straight line for the LOD and LOQ determination. Following the approach of Mermet (2008), and using the non-weighted calibration at the $1 \sigma$ confidence level, the LOD and LOQ for peak area normalized at $766 \mathrm{~nm}$, determined by reference samples, are 0.14 and 0.52 wt.\%, respectively. The LOD and LOQ for peak area normalized at $770 \mathrm{~nm}$ are 0.05 and $0.19 \mathrm{wt} . \%$, respectively.

In order to assess the accuracy and the precision of the quantification deduced from our calibration, based on standard glasses and minerals (plagioclase, amphibole and phlogopite) analyses and used to determine $\mathrm{K}$ content of crystals, several measurements on Viluy samples (TL18, TL19, 30-01), ADB and AMP3.8 have been performed. Table 5 shows that K contents determined using LIBS analyses range from $0.254 \pm 0.090$ to $0.401 \pm 0.078$ wt. K\%. These values have relative standard deviations $(\sigma)$ ranging from 7 to $35 \%$, and are consistent at the $2-\sigma$ level with reference $\mathrm{K}$ contents determined with spectrophotometry. Note that, although AMP3.8 plagioclase and amphibole crystals were used to obtain the calibration curve shown 
in Fig. 5, analyses presented in Table 5 for this sample have been obtained from different laser shots, and can be considered as internal checks for our calibration.

The accuracy of the univariate model is characterized by calculating the calibration error called the root-mean-square error prediction (RMSEP in the units of the predicted quantity, i.e. wt. \%) of cross validation between the concentrations of the laboratory standards measured and the calculated predictions (El Haddad et al., 2014; Wiens et al., 2013). The RMSEP is calculated by the following expression:

$R M S E P=\sqrt{\frac{\sum_{i=1}^{N}(r i-p i)^{2}}{N}}$

where pi is the predicted value, ri is the reference value, and $\mathrm{N}$ is the number of samples in the dataset. Based on data from Table 5, the RMSEP, which is calculated for the potassium value obtained from 50 spectra analyzed on a set of reference samples with $\mathrm{K}$ contents between 0.2 and $0.5 \%$, is \pm 0.1 wt. $\%$ (Table 5 ).

\subsubsection{QMS Ar data}

As a very small amount of sample is evaporated during ablation (between 10 and $50 \mu \mathrm{g}$ ), ${ }^{40} \mathrm{Ar}$ and ${ }^{36} \mathrm{Ar}$ were measured with an electron multiplier (EM). From several analyses on SCD, the EM sensitivity is defined at $1.47 \times 10^{-21} \mathrm{~A} /$ atom and its quantification limits at $3 \times 10^{8}$ atoms $\left(5 \times 10^{-16}\right.$ moles $)$.

The uncertainty defined by the relative standard deviation on the signal, is lower than $5 \%$ for ${ }^{36} \mathrm{Ar}$, and lower than $1 \%$ for ${ }^{40} \mathrm{Ar}$. In addition, taking into account an uncertainty on the argon signal calibration of $1.2 \%$ (based on repeated measurements of the calibration dose and standards LP6 and GLO, and reference samples; Fig. 2), the overall relative uncertainty on the number of argon atoms determination is $5.2 \%$ for ${ }^{36} \mathrm{Ar}$, and $1.6 \%$ for ${ }^{40} \mathrm{Ar}$. 
QMS blank for ${ }^{36} \mathrm{Ar}$ is $2.9 \pm 0.4 \times 10^{-17}$ moles, and is $<3 \times 10^{-16}$ moles for ${ }^{40} \mathrm{Ar}$, which precludes the accurate measurement of small ${ }^{36} \mathrm{Ar}$ signals. Indeed, the signal to noise ratio $(\mathrm{S} / \mathrm{N})$ for one SCD is about 10 for the ${ }^{36} \mathrm{Ar}$, and does not exceed 1 for the ${ }^{36} \mathrm{Ar}$ released by a sample ablation. Hence, it cannot be considered as significative, and therefore all the measured ${ }^{40} \mathrm{Ar}$ is considered as radiogenic. It is important to note that ${ }^{36} \mathrm{Ar}$ is used here only to check for the absence of anomalous atmospheric contamination produced during the preparation or following unexpected ablation of a vesicle.

Fig. 6a shows the linearity of our QMS response, based on analysis of several successive increments of SCD (from 1 to 5 air pipettes), providing ${ }^{40} \mathrm{Ar}$ signals between 6 and $30 \times 10^{-11}$ A. Similarly, Fig. $6 \mathrm{~b}$ presents the 3 distinct comparisons between measured ${ }^{40} \mathrm{Ar}$ signal evolution during 15 successive decrement experiments of one SCD (successively expended in the whole-line volume - QMS isolated and line pumped for each experiment), compared to theoretical values calculated from successive expansions. Such experiments highlight the linearity of the instrument in the range 0.2 to $30 \times 10^{-11} \mathrm{~A}$, corresponding to a range from 9.7 $\mathrm{x} 10^{8}$ to $1.7 \times 10^{11}$ atoms of ${ }^{40} \mathrm{Ar}$, which is much wider than typical signals expected for the analogue samples of the Martian rocks.

Analyses of AMP3.8, ADB and 30-01 were achieved with an ablation time between 15 and 90 seconds (see section 4.3.1.). The results obtained on AMP3.8 show a range of ${ }^{40} \mathrm{Ar}$ between 10 and $70 \times 10^{9}$ atoms. The values used for mass determination obtained for ADB are between 4 and $35 \times 10^{9}$ atoms, and they are between 1 and $7 \times 10^{9}$ atoms for $30-01$. This highlights the satisfactory QMS behavior over a large range of ${ }^{40} \mathrm{Ar}$ content. 


\subsubsection{Ablated mass determination}

Fig. 7 shows ablation craters images obtained by profilometer and scanning electron microscopy (SEM) for phlogopite 15-yates-1-bio and amphibolite AMP3.8. SEM images show the roughness of craters morphology, which renders the accurate volume determination difficult. This is further highlighted by the raw images of profilometry data. Indeed, no measurement (NM in Fig. 7) could be obtained on most of AMP3.8 surface. On the other hand, when applied to single crystals such as phlogopite, profilometry data acquisition was more straightforward. Using a mineral density of 2.8 g.cm³, a volume of $8.1 \pm 0.8 \mu \mathrm{g}$ was obtained for 15-yates-1-bio for the crater shown in Fig. 7. For both samples, Fig. 8 shows the correlation between the ablated mass obtained by profilometry technique, and the ablated mass determined from ${ }^{40} \mathrm{Ar}$ content and QMS measurements (see section 3.2.). The correlation appears very good for craters performed on phlogopite (15-yates-1-bio). Nevertheless, Fig. 8 clearly shows that no correlation exists for amphibolite AMP3.8, probably due to the poor profilometry volume determination for such rock sample.

The mass determination based on the profilometry technique remains unsatisfactorily, because i) the shape of the ablation crater is often irregular and perturbated by ejecta deposits; ii) ablation may be variable from one spot to the other depending on variable mineral strength; and iii) calculation of the ablated mass is based on an a priori value of the mineral density, which can vary greatly depending on composition; and iv) the surface color (made of single or polyminerals) and the visibility of the bottom of the crater affect the accuracy of the profilometry technique, impacting directly volume and mass determinations. Consequently, we will only rely on the volume determination based on the QMS measurements, which can provide mass measurement from the released amount of ${ }^{40} \mathrm{Ar}$ with a relative uncertainty as low as $2 \%$. Such approach requires to establish a well-defined correlation between the ablated 
mass and the ablation time, for all mineralogical facies of interest for Martian dating, and, thus, multiple measurements from different mineral phases are needed.

Several analyses of plagioclase crystals of ADB, AMP3.8 and 30-01 allowed us to define the relation between the ablation time and the ablated mass (Fig. 9). The ablated mass is obtained by comparison between number of atoms measured by QMS and content of ${ }^{40} \mathrm{Ar} *$ atoms per gram determined by the K-Ar Cassignol-Gillot technique with $11.8 \times 10^{14}$ atoms per gram for plagioclases of ADB (this study), $11.5 \times 10^{14}$ atoms per gram for plagioclases of AMP3.8 (this study), and $1.5 \times 10^{14}$ atoms per gram for plagioclases of 30-01 (Courtillot et al., 2010). Fig. 9a shows data for each selected plagioclase from each sample in order to obtain the correlation between the ablated mass and the ablation time. Fig $9 \mathrm{~b}$ shows the data average and the associated uncertainty of these plagioclases for each sample at different ablation time. Finally, Fig. 9c shows the average of ablated mass sample according to ablation time. The uncertainty was defined from the relative dispersion of average data obtained for each sample at given ablation time, and the uncertainty on the slope of $4 \%$ is obtained using Mahon (1996).

\section{Discussion}

\subsection{K data: Comparison between LIBS and other methods for $K$ determination}

Optic spectroscopy (LIBS) K measurements, that are used for in-situ dating with KArMars, have been compared with in-situ Electron micro-analysis (EPMA), spectrometry (ICP-OES), and spectrophotometry achieved on mineral separates (Table 6).

The results obtained by the two different in-situ techniques (EPMA and LIBS) on the amphibole from AMP3.8 are in agreement within uncertainties, while those for plagioclase of the same rock show significant discrepancy. This can be explained by the difference in size of the two spots (EPMA and LIBS), and by the chemical heterogeneity of the plagioclase 
phenocrysts, which show significant mineral crystal zoning. Indeed, EPMA provide analyses with a beam diameter of $5 \mu \mathrm{m}$ only, which is much smaller than the typical beam size of our U-V laser. While the latter averages different parts of the mineral, including K-rich crystal zoning in their outer rim, and inclusions (e.g., amphiboles as observed in thin section), the very low-K concentration obtained by EPMA indicates that punctual analysis reached a zone depleted in K. In turn, sericite alteration is also present in most plagioclase crystals (McDougall and Harrison, 1999). It induces small-scale re-crystallization of fine-grained muscovite, with K-rich composition, within plagioclase crystals. In contrast, LIBS analyses are performed with a beam diameter of about $300 \mu \mathrm{m}$, thereby averaging out these heterogeneities, if present (mineral sizes from this study range between $50 \mu \mathrm{m}$ and $2 \mathrm{~mm}$ ). Nevertheless, the good agreement between the other results obtained from spot-by-spot analyses, at various location in a given sample, shows a relatively even $\mathrm{K}$ distribution, taking into account the uncertainty of each analysis.

LIBS $\mathrm{K}$ values obtained on AMP3.8 and ADB samples are in good agreement with those obtained by spectrophotometry. This validates the use of these pure mineral standards in order to calibrate our in-situ dating instrument. However, K content obtained for 30-01 sample by LIBS is significantly different from spectrophotometry data. Indeed, the plagioclase phenocrysts $(0.5-1 \mathrm{~mm})$ show a lower K content $(0.202 \mathrm{wt} . \%)$ but yield consistent ages (at the 1 sigma level) with the plagioclase crystals present in the microlite fraction $(0.12-0.25 \mathrm{~mm}$; 0.355 wt.\% of K) (Courtillot et al., 2010). Hence, because it is not possible to determine which crystal fraction is hit by the laser spot, LIBS K values range between 0.202 and 0.355 wt.\%, which are the K contents of phenocrysts and microcrysts, respectively (Table 6).

LIBS data provide very valuable information for the interpretation of each ablation, and eventually to perform a better data correction. Effectively, major elements LIBS measurements allow to identify which mineral phase was ablated, or if it is a mix between 
several minerals, and furthermore, if it is suitable for $\mathrm{K}$-Ar dating. The uncertainty of $\mathrm{K}$ content determination using LIBS, mainly due to plasma fluctuation during ablation time and the rock heterogeneity at the sub-millimeter scale, is the most limiting factor of the KArMars method because it dominates the uncertainty of $\mathrm{K}$-Ar ages. In order to minimize these fluctuations and the heterogeneity effects, short duration ablations should be preferred.

\subsection{Using KArMars for in-situ dating}

In order to test the KArMars instrument for in-situ K-Ar dating, terrestrial analogues to Martian rocks with a large range of crystals size (supp. Fig. 1), have been selected. UV laser ablations with 150 to 900 laser pulses were performed on amphibolite (AMP3.8) from Nuvvuagittuq, enderbite (ADB) from Churchill Province, and basalts (30-01, TL-18, TL-19, TO-35) from Viluy Traps (This study; Courtillot et al., 2010; Ricci et al., 2013) used here as unknowns. Results obtained by QMS, LIBS and mass calibration (based on reference samples analyses) are given in supp. Table 2 . The main source of age uncertainty is due to the LIBS measurements, as $\mathrm{K}$ uncertainties range between 5 and $40 \%$ (supp. Table 2). The uncertainty on ${ }^{40} \mathrm{Ar}$ measurement is about $2 \%$ (supp. Table 2), and the uncertainty on mass determination obtained using reference samples, is about $4 \%$. Propagating these independent sources of uncertainty gives a total relative uncertainty on the age between 7 and $40 \%$ for a typical single ablation. KArMars ages of these samples have been determined using the isochron approach (Fig. 10) and are compared with the reference K-Ar ages in Table 7.

The results obtained on AMP3.8 show K content between 0.19 and 0.39 wt.\% (K\% reference of plagioclase: $0.29 \%$; Table 3), and a range of ${ }^{40}$ Ar between 5 and $70 \times 10^{9}$ atoms (supp. Table 2). The isochron age obtained for plagioclase minerals is $2218 \pm 135 \mathrm{Ma}$ (Fig. 10), which yields an uncertainty of $6 \%$ and a difference with the reference age of about $8 \%$ (Table 7). The correlation defined for the determination of the ablated mass on plagioclase was also 
tested on other mineral phases from sample AMP3.8 (Fig. 10): i) pure amphibole and ii) mixture of amphibole and plagioclase (mix phases), because analysis of pure plagioclase minerals from this sample was not always possible since many crystals have sizes $(<250 \mu \mathrm{m}$; supp. Fig 1) smaller than the laser beam diameter. In addition, amphibole inclusions in some plagioclase crystals are also observed (supp. Fig. 1). The isochron age obtained for amphibole minerals is $2913 \pm 292 \mathrm{Ma}$, with an accuracy of $8 \%$ relative to the reference age (Table 7), while an age of $2585 \pm 138 \mathrm{Ma}$ is obtained for mixtures of plagioclase/amphibole minerals. As expected, the later is between the reference ages of $2052 \pm 29$ and $2649 \pm 38 \mathrm{Ma}$, for plagioclase and amphibole crystals, respectively (Table 7). It can be noted that this rock presents a complex geological history, which will probably not be the case for basalts of the Martian surface formed during the first $2 \mathrm{Ga}$.

The results obtained on ADB plagioclase show $\mathrm{K}$ contents ranging from 0.22 to 0.53 wt.\% (K\% reference: $0.5 \%$; Table 3), and ${ }^{40} \mathrm{Ar}$ contents between 4 and $35 \times 10^{9}$ atoms (supp. Table 2). The isochron age is $1382 \pm 46 \mathrm{Ma}$ (Fig. 10), showing an uncertainty of $3 \%$ and a difference with the reference age of about $6 \%$ (Table 7). Such very good agreement has been favored by the size of the plagioclase crystals, which are much larger than the laser beam, thereby reducing the risk to dig through the mineral and ablate a mix between several phases.

Four basaltic samples from the Devonian Viluy Traps (Courtillot et al., 2010; Ricci et al., 2013) have also been dated in order to test the limits of KArMars. 30-01, TL-18, and TL-19 have plagioclase sizes between $250-500 \mu \mathrm{m}$, which allow pure minerals to be ablated, while TO-35 has much finer grains.

$\mathrm{K}$ contents obtained for 30-01 plagioclase minerals are between 0.26 and $0.30 \mathrm{wt} . \%$, within the range of reference values previously reported (Courtillot et al., 2010), and ${ }^{40} \mathrm{Ar}$ content ranging between 1 and $4 \times 10^{9}$ atoms (supp. Table 2). An isochron age of $351 \pm 33 \mathrm{Ma}$ is 
obtained for this sample (Fig. 10). It shows an uncertainty of $10 \%$ and a difference with the reference age of about 5\% (Table 7). $\mathrm{K}$ contents ranging from 0.21 to 1.45 wt.\% (K\% reference of plagioclase: $0.35 \%$; Ricci et al., 2013), and ${ }^{40} \mathrm{Ar}$ contents ranging from 1 to $10 \times 10^{9}$ atoms have been obtained for TL-18 (supp. Table 2). It yields an isochron age of 362 \pm 15 Ma for TL-18 plagioclases (Fig. 10), displaying an uncertainty of $4 \%$ and a difference with the reference age of about $5 \%$ (Table 7). Similarly, the age of $358 \pm 20$ Ma obtained for plagioclases of TL19 (Fig. 10) has an uncertainty of 6\%, and a difference with the reference age about 5\% (Table 7). It has been obtained from $\mathrm{K}$ contents ranging between 0.13 and 0.66 wt. $\%$, and ${ }^{40} \mathrm{Ar}$ contents between 0.4 and $8 \times 10^{9}$ atoms (supp. Table 2). The correlation line gives an age of $358 \pm 20 \mathrm{Ma}$. Finally, TO-35 shows a range of $\mathrm{K}$ content from 0.12 to 0.22 wt.\%, and a number of ${ }^{40} \mathrm{Ar}$ atoms between 0.4 and $3 \times 10^{9}$ (supp. Table 2). As expected from its low K content and texture, the isochron age of $406 \pm 210 \mathrm{Ma}$ (Fig. 10) displays a relatively large uncertainty of $52 \%$. However, the difference with the reference age is only $9 \%$ (Table 7; Fig. 11).

Finally, the comparison shown in Fig. 11 highlights the accuracy of KArMars ages, which all are within $10 \%$ only of their reference age (Table 7 ). This is even observed for relatively young and low $\mathrm{K}$ samples from Viluy basalts, which are at the limit of detection of the instruments composing the KArMars setting.

\section{Conclusions}

In this study, we developed and calibrated a new in-situ K-Ar dating instrument (KArMars) based on LIBS for K measurements, QMS for Ar determinations, and analyses of reference samples for calibration of the ablated mass. Note that several components used here in KArMars have already been adapted for planetary exploration. Onboard rover Curiosity, the 
Sample Analysis at Mars instrument (SAM), includes a QMS suitable for noble gas analyses of Martian rocks, and the ChemCam experiment runs a LIBS instrument.

We have shown that the sample mass released during short duration UV-laser ablation can be successfully determined by QMS analyses of a set of reference samples for which the ${ }^{40} \mathrm{Ar}$ content has been previously precisely determined.

In-situ K-Ar ages obtained here with KArMars on Viluy basalts, ADB and AMP3.8 samples have been validated by the comparison with their reference ages obtained using classic $\mathrm{K}-\mathrm{Ar}$ measurements (Fig. 11; Table 7). The expected $\mathrm{K}$ and Ar contents on Mars are quite similar than those of amphibolite AMP3.8 and enderbite ADB successfully analyzed here (Fig. 10). Furthermore, despite the low Ar content of Viluy samples, due to their relative young age, and their small-scale textural heterogeneity, the KArMars instrument was able to provide consistent ages, with less than $15 \%$ of uncertainty. Overall, our results clearly show that the KArMars approach can be successfully used for dating a large compositional range of Martian rocks, with uncertainties as low as about $10 \%$, and with accuracy, i.e. difference with the reference age, of only $10 \%$. Furthermore, these results validate our approach based on reference samples for mass determination.

\section{Acknowledgments}

This work has been funded by the Centre National d'Etudes Spatiales (CNES; Project "Datation Potassium-Argon sur Mars", grants R-S17/SU-0003-043 and R-S16/SU-0003-043) and the Université Paris Sud (part of F.C. PhD grant). We are grateful to Cécile Fabre for detailed comments that significantly improved the manuscript. We acknowledge the ChemCam team, particularly S. Maurice, O. Gasnault, V. Sautter, A. Cousin and P.-Y. Meslin, for help and advice during the development of KArMars. We wish to thank D. Pinti 
for its help to find old reference samples. We thank J.-B. Sirven for his assistance with LIBS theory. We thank L. Djemel and K. Kateryna for giving us the opportunity to use profilometer and SEM systems, and the Laboratoire Magmas et Volcans for using EPMA. Finally, we acknowledge V. Godard, C. Lanoé, C. Drag and P. Pariset for their help during the instrumental development. 


\section{References}

Anderson, F.S., Levine, J., Whitaker, T.J., 2015. Dating the Martian meteorite Zagami by the 87Rb$87 \mathrm{Sr}$ isochron method with a prototype in situ resonance ionization mass spectrometer. Rapid Commun. Mass Spectrom. 29, 191-204. doi:10.1002/rcm.7095

Aragon, C., Penalba, F., Aguilera, J.A., 1999. Improvements in Quantitative Analysis of Steel Composition by Laser-Induced Breakdown Spectroscopy at Atmospheric Pressure Using an Infrared Nd:YAG Laser. Appl. Spectrosc. 53, 1259-1267.

Baksi, A.K., Archibald, D.A., Farrar, E., 1996. Intercalibration of 40Ar39Ar dating standards. Chem. Geol. 129, 307-324. doi:10.1016/0009-2541(95)00154-9

Barfod, G.H., Krogstad, E.J., Frei, R., Albarède, F., 2005. Lu-Hf and PbSL geochronology of apatites from Proterozoic terranes: A first look at Lu-Hf isotopic closure in metamorphic apatite. Geochim. Cosmochim. Acta 69, 1847-1859. doi:10.1016/j.gca.2004.09.014

Bibring, J.P., Langevin, Y., Mustard, J.F., Poulet, F., Arvidson, R., Gendrin, A., Gondet, B., Mangold, N., Pinet, P., Forget, F., Berthé, M., Bibring, J.-P., Gendrin, A., Gomez, C., Gondet, B., Jouglet, D., Poulet, F., Soufflot, A., Vincendon, M., Combes, M., Drossart, P., Encrenaz, T., Fouchet, T., Merchiorri, R., Belluci, G., Altieri, F., Formisano, V., Capaccioni, F., Cerroni, P., Coradini, A., Fonti, S., Korablev, O., Kottsov, V., Ignatiev, N., Moroz, V., Titov, D., Zasova, L., Loiseau, D., Mangold, N., Pinet, P., Douté, S., Schmitt, B., Sotin, C., Hauber, E., Hoffmann, H., Jaumann, R., Keller, U., Arvidson, R., Mustard, J.F., Duxbury, T., Forget, F., Neukum, G., 2006. Global Mineralogical and Aqueous Mars History Derived from OMEGA/Mars Express Data. Science 312, 400-404. doi:10.1126/science.1122659

Body, D., Chadwick, B.L., 2001. Optimization of the spectral data processing in a LIBS simultaneous elemental analysis system. Spectrochim. Acta Part B At. Spectrosc. 56, 725-736. doi:10.1016/S0584-8547(01)00186-0

Bogard, D.D., 2009. K-Ar dating of rocks on Mars: Requirements from Martian meteorite analyses and isochron modeling. Meteorit. Planet. Sci. 44, 3-14. doi:10.1111/j.1945-5100.2009.tb00713.x

Bogard, D.D., Park, J., 2008. 39Ar-40Ar dating of the Zagami Martian shergottite and implications for magma origin of excess 40Ar. Meteorit. Planet. Sci. 43, 1113-1126. doi:10.1111/j.19455100.2008.tb01116.x

Boynton, W. V., Taylor, G.J., Evans, L.G., Reedy, R.C., Starr, R., Janes, D.M., Kerry, K.E., Drake, D.M., Kim, K.J., Williams, R.M.S., Crombie, M.K., Dohm, J.M., Baker, V., Metzger, A.E., Karunatillake, S., Keller, J.M., Newsom, H.E., Arnold, J.R., Brückner, J., Englert, P.A.J., Gasnault, O., Sprague, A.L., Mitrofanov, I., Squyres, S.W., Trombka, J.I., D’Uston, L., Wänke, H., Hamara, D.K., 2007. Concentration of H, Si, Cl, K, Fe, and Th in the low- and mid-latitude regions of Mars. J. Geophys. Res. 112, E12S99. doi:10.1029/2007JE002887

Cabalin, L.M., Laserna, J.J., 1998. Experimental determination of laser induced breakdown thresholds of metals under nanosecond Q-switched laser operation. Spectrochim. Acta Part B 53, 723-730. doi:10.1016/S0584-8547(98)00107-4

Cattani, F., Gillot, P.Y., Hildenbrand, A., Quidelleur, X., Courtade, F., Boukari, C., Lefevre, J.C., 2017. Realization of a collection of reference minerals to develop a technique for in situ dating of the Martian rocks, in: American Geophysical Union, Fall Meeting 2017, New Orleans, Abstract \#V13B-0382.

Cheilletz, A., Archibald, D.A., Cuney, M., Charoy, B., 1992. 40Ar/39Ar ages of the Beauvoir topaze- 
lepidolite leucogranite and the Chedeville sodolithic pegmatite (northern Massif Central, France). Petrologic and geodynamic significance. Comptes Rendus l'Academie des Sci. Ser. II 315, 329336.

Cho, Y., Miura, Y.N., Sugita, S., 2013. Development of an in-situ K-Ar isochron dating method using LIBS-QMS configuration, in: 44th Lunar and Planetary Science Conference. The Woodlands, Texas, p. 1505.

Cho, Y., Sugita, S., Kameda, S., Miura, Y.N., Ishibashi, K., Ohno, S., Kamata, S., Arai, T., Morota, T., Namiki, N., Matsui, T., 2015. High-precision potassium measurements using laser-induced breakdown spectroscopy under high vacuum conditions for in situ $\mathrm{K}$-Ar dating of planetary surfaces. Spectrochim. Acta Part B At. Spectrosc. 106, 28-35. doi:10.1016/j.sab.2015.02.002

Cho, Y., Sugita, S., Miura, Y.N., Okazaki, R., Iwata, N., Morota, T., Kameda, S., 2016. An in-situ KAr isochron dating method for planetary landers using a spot-by-spot laser-ablation technique. Planet. Space Sci. 128, 14-29. doi:10.1016/j.pss.2016.05.004

Cho, Y., Cohen, B.A., 2018. Dating igneous rocks using the Potassium-Argon Laser Experiment (KArLE) instrument: A case study for $\sim 380$ Ma basaltic rocks. Rapid Commun. Mass Spectrom. 32, 1755-1765. doi:10.1002/rcm.8214

Christensen, P.R., McSween, H.Y., Bandfield, J.L., Ruff, S.W., Rogers, A.D., Hamilton, V.E., Gorelick, N., Wyatt, M.B., Jakosky, B.M., Kieffer, H.H., Malin, M.C., Moersch, J.E., 2005. Evidence for magmatic evolution and diversity on Mars from infrared observations. Nature 436, 504-509. doi:10.1038/nature04075

Clegg, S.M., Sklute, E., Dyar, M.D., Barefield, J.E., Wiens, R.C., 2009. Multivariate analysis of remote laser-induced breakdown spectroscopy spectra using partial least squares, principal component analysis, and related techniques. Spectrochim. Acta Part B At. Spectrosc. 64, 79-88. doi:10.1016/J.SAB.2008.10.045

Coche, M., Berthoud, T., Mauchien, P., Camus, P., 1989. Laser-Enhanced Ionization Detection in a Laser-Produced Plasma at Atmospheric Pressure: Theoretical and Experimental Considerations. Appl. Spectrosc. 43, 646-650. doi:10.1366/0003702894202661

Cohen, B.A., Miller, J.S., Li, Z.H., Swindle, T.D., French, R.A., 2014. The potassium-argon laser experiment (KArLE): In situ geochronology for planetary robotic missions. Geostand. Geoanalytical Res. 38, 421-439. doi:10.1111/j.1751-908X.2014.00319.x

Coulié, E., Quidelleur, X., Lefèvre, J.C., Gillot, P.-Y., 2004. Exploring the multicollection approach for the $40 \mathrm{Ar} / 39 \mathrm{Ar}$ dating technique. Geochemistry, Geophys. Geosystems 5. doi:10.1029/2004GC000773

Courtillot, V., Kravchinsky, V.A., Quidelleur, X., Renne, P.R., Gladkochub, D.P., 2010. Preliminary dating of the Viluy traps (Eastern Siberia): Eruption at the time of Late Devonian extinction events? Earth Planet. Sci. Lett. 300, 239-245. doi:10.1016/j.eps1.2010.09.045

Cousin, A., Sautter, V., Payré, V., Forni, O., Mangold, N., Gasnault, O., Le Deit, L., Johnson, J., Maurice, S., Salvatore, M., Wiens, R.C., Gasda, P., Rapin, W., 2017. Classification of igneous rocks analyzed by ChemCam at Gale crater, Mars. Icarus 288, 265-283. doi:10.1016/j.icarus.2017.01.014

Cremers, D.A., Knight, A.K., 2000. Laser-Induced Breakdown Spectroscopy, in: Encyclopedia of Analytical Chemistry. John Wiley \& Sons, Ltd, Chichester, UK.

doi:10.1002/9780470027318.a5110t 
Cremers, D.A., Radziemski, L.J., 2006. Handbook of Laser-Induced Breakdown Spectroscopy. doi:10.1002/0470093013

Cremers, D.A., Radziemski, L.J., 1983. Detection of chlorine and fluorine in air by laser-induced breakdown spectrometry. Anal. Chem. 55, 1252-1256. doi:10.1021/ac00259a017

David, J., Godin, L., Stevenson, R.K., O’Neil, J., Francis, D., 2009. U-Pb ages (3.8-2.7 Ga) and Nd isotope data from the newly identified Eoarchean Nuvvuagittuq supracrustal belt, Superior Craton, Canada. Geol. Soc. Am. Bull. 121, 150-163. doi:10.1130/B26369.1

Davis, D.W., Lafrance, I., Goutier, J., Takam, F.T., Bandyayera, D., Gigon, J., Francis, C.:, Takam, T., 2018. Datations U-Pb dans les provinces de Churchill et du Supérieur effectuées au JSGL en 2013-2014 (RP 2017-01).

Devismes, D., Gillot, P.Y., Lefèvre, J.C., Boukari, C., Rocard, F., Chiavassa, F., 2016. KArMars: A Breadboard Model for In Situ Absolute Geochronology Based on the K-Ar Method Using UVLaser Induced Breakdown Spectroscopy and Quadrupole Mass Spectrometry. Geostand. Geoanalytical Res. 40, 517-532. doi:10.1111/ggr.12118

Doran, P.T., Clifford, S.M., Forman, S.L., Nyquist, L., Papanastassiou, D.A., Stewart, B.W., Sturchio, N.C., Swindle, T.D., Cerling, T., Kargel, J., McDonald, G., Nishiizumi, K., Poreda, R., Rice, J.W., Tanaka, K., 2004. Mars chronology: Assessing techniques for quantifying surficial processes. Earth-Science Rev. 67, 313-337. doi:10.1016/j.earscirev.2004.04.001

Dyar, M.D., Tucker, J.M., Humphries, S., Clegg, S.M., Wiens, R.C., Lane, M.D., 2011. Strategies for Mars remote Laser-Induced Breakdown Spectroscopy analysis of sulfur in geological samples. Spectrochim. Acta - Part B At. Spectrosc. 66, 39-56. doi:10.1016/j.sab.2010.11.016

Effenberger, A.J., Scott, J.R., 2010. Effect of atmospheric conditions on LIBS spectra. Sensors 10, 4907-4925. doi:10.3390/s100504907

El Haddad, J., Canioni, L., Bousquet, B., 2014. Good practices in LIBS analysis: Review and advices. Spectrochim. Acta - Part B At. Spectrosc. 101, 171-182. doi:10.1016/j.sab.2014.08.039

Fabre, C., Cousin, A., Wiens, R.C., Ollila, A., Gasnault, O., Maurice, S., Sautter, V., Forni, O., Lasue, J., Tokar, R., Vaniman, D., Melikechi, N., 2014. In situ calibration using univariate analyses based on the onboard ChemCam targets: First prediction of Martian rock and soil compositions. Spectrochim. Acta - Part B At. Spectrosc. 99, 34-51. doi:10.1016/j.sab.2014.03.014

Fabre, C., Maurice, S., Cousin, A., Wiens, R.C., Forni, O., Sautter, V., Guillaume, D., 2011. Onboard calibration igneous targets for the mars science laboratory curiosity rover and the chemistry camera laser induced breakdown spectroscopy instrument. Spectrochim. Acta - Part B At. Spectrosc. 66, 280-289. doi:10.1016/j.sab.2011.03.012

Farley, K.A., Hurowitz, J.A., Asimow, P.D., Jacobson, N.S., Cartwright, J.A., 2013. A double-spike method for K-Ar measurement: A technique for high precision in situ dating on Mars and other planetary surfaces. Geochim. Cosmochim. Acta 110, 1-12. doi:10.1016/j.gca.2013.02.010

Farley, K.A., Malespin, C., Mahaffy, P., Grotzinger, J.P., Vasconcelos, P.M., Milliken, R.E., Malin, M., Edgett, K.S., Pavlov, A.A., Hurowitz, J.A., Grant, J.A., Miller, H.B., Arvidson, R., Beegle, L., Calef, F., Conrad, P.G., Dietrich, W.E., Eigenbrode, J., Gellert, R., Gupta, S., Hamilton, V., Hassler, D.M., Lewis, K.W., McLennan, S.M., Ming, D., Navarro-Gonzalez, R., Schwenzer, S.P., Steele, A., Stolper, E.M., Sumner, D.Y., Vaniman, D., Vasavada, A., Williford, K., Wimmer-Schweingruber, R.F., MSL Science Team, 2014. In Situ Radiometric and Exposure Age Dating of the Martian Surface. Science 343, 1247166-1247166. 
Faure, G., 1986. Principles of isotope geology. John Wiley and Sons Inc., New York, NY.

Forget, F., Costard, F., Lognonné, P., 1999. La planète Mars : Histoire d'un autre monde.

Fuhrmann, U., Lippolt, H.J., Hess, J.C., 1987. Examination of some proposed K-Ar standards: 40Ar39Ar analyses and conventional KAr data. Chem. Geol. Isot. Geosci. Sect. 66, 41-51. doi:10.1016/0168-9622(87)90027-3

Garner, L., Murphy, T.J., Gramlich, J.W., Paulsen, P.J., Barnes, I.L., 1975. Absolute Isotopic Abundance Ratios and the Atomic Weight of a Reference Sample of Potassium. J. Res. Natl. Bur. Stand. 79A, 713-725.

Gillot, P.Y., Cornette, Y., 1986. The Cassignol technique for potassium-Argon dating, precision and accuracy: Examples from the Late Pleistocene to Recent volcanics from southern Italy. Chem. Geol. Isot. Geosci. Sect. 59, 205-222. doi:10.1016/0168-9622(86)90072-2

Gillot, P.Y., Cornette, Y., Max, N., Floris, B., 1992. Two reference materials, trachytes MDO-G and ISH-G, for argon dating (K-Ar and 40Ar/39Ar) of Pleistocene and Holocene rocks. Geostand. Geoanalytical Res. 16, 55-60. doi:10.1111/j.1751-908X.1992.tb00487.x

Gillot, P.Y., Hildenbrand, A., Lefèvre, J.C., Albore Livadie, C., 2006. The K/Ar dating method: principle, analytical techniques, and application to holocene volcanic eruptions in Southern Italy. Acta Vulcanol. 18, 55-66.

Goueguel, C., Singh, J.P., McIntyre, D.L., Jain, J., Karamalidis, A.K., 2014. Effect of Sodium Chloride Concentration on Elemental Analysis of Brines by Laser-Induced Breakdown Spectroscopy (LIBS). Appl. Spectrosc. 68, 213-221. doi:10.1366/13-07110

Guezenoc, J., Bassel, L., Gallet-Budynek, A., Bousquet, B., 2017. Variables selection: A critical issue for quantitative laser-induced breakdown spectroscopy. Spectrochim. Acta Part B At. Spectrosc. 134, 6-10. doi:10.1016/j.sab.2017.05.009

Hartmann, W.K., 2005. Martian cratering 8: Isochron refinement and the chronology of Mars. Icarus 174, 294-320. doi:10.1016/j.icarus.2004.11.023

Heier, K.S., Adams, J.A.S., 1964. The geochemistry of the alkali metals. Phys. Chem. Earth 5, $253-$ 381. doi:10.1016/S0079-1946(64)80007-0

Jochum, K.P., Willbold, M., Raczek, I., Stoll, B., Herwig, K., 2005. Chemical Characterisation of the USGS Reference Glasses GSA-1G, GSC-1G, GSD-1G, GSE-1G, BCR-2G, BHVO-2G and BIR$1 \mathrm{G}$ Using EPMA, ID-TIMS, ID-ICP-MS and LA-ICP-MS. Geostand. Geoanalytical Res. 29, 285-302. doi:10.1111/j.1751-908X.2005.tb00901.x

Mahaffy, P.R., Webster, C.R., Cabane, M., Conrad, P.G., Coll, P., Atreya, S.K., Arvey, R., Barciniak, M., Benna, M., Bleacher, L., Brinckerhoff, W.B., Eigenbrode, J.L., Carignan, D., Cascia, M., Chalmers, R.A., Dworkin, J.P., Errigo, T., Everson, P., Franz, H., Farley, R., Feng, S., Frazier, G., Freissinet, C., Glavin, D.P., Harpold, D.N., Hawk, D., Holmes, V., Johnson, C.S., Jones, A., Jordan, P., Kellogg, J., Lewis, J., Lyness, E., Malespin, C.A., Martin, D.K., Maurer, J., McAdam, A.C., McLennan, D., Nolan, T.J., Noriega, M., Pavlov, A.A., Prats, B., Raaen, E., Sheinman, O., Sheppard, D., Smith, J., Stern, J.C., Tan, F., Trainer, M., Ming, D.W., Morris, R. V., Jones, J., Gundersen, C., Steele, A., Wray, J., Botta, O., Leshin, L.A., Owen, T., Battel, S., Jakosky, B.M., Manning, H., Squyres, S.W., Navarro-González, R., McKay, C.P., Raulin, F., Sternberg, R., Buch, A., Sorensen, P., Kline-Schoder, R., Coscia, D., Szopa, C., Teinturier, S., Baffes, C., Feldman, J., Flesch, G., Forouhar, S., Garcia, R., Keymeulen, D., Woodward, S., Block, B.P., 
Arnett, K., Miller, R., Edmonson, C., Gorevan, S., Mumm, E., 2012. The Sample Analysis at Mars Investigation and Instrument Suite. Space Sci. Rev. 170, 401-478. doi:10.1007/s11214012-9879-Z

Mahon, K.I., 1996. The New "York" Regression: Application of an Improved Statistical Method to Geochemistry. Int. Geol. Rev. 38, 293-303. doi:10.1080/00206819709465336

Maurice, S., Wiens, R.C., Saccoccio, M., Barraclough, B., Gasnault, O., Forni, O., Mangold, N., Baratoux, D., Bender, S., Berger, G., Bernardin, J., Berthé, M., Bridges, N., Blaney, D., Bouyé, M., Caïs, P., Clark, B., Clegg, S., Cousin, A., Cremers, D., Cros, A., DeFlores, L., Derycke, C., Dingler, B., Dromart, G., Dubois, B., Dupieux, M., Durand, E., D’Uston, L., Fabre, C., Faure, B., Gaboriaud, A., Gharsa, T., Herkenhoff, K., Kan, E., Kirkland, L., Kouach, D., Lacour, J.-L., Langevin, Y., Lasue, J., Le Mouélic, S., Lescure, M., Lewin, E., Limonadi, D., Manhès, G., Mauchien, P., McKay, C., Meslin, P.-Y., Michel, Y., Miller, E., Newsom, H.E., Orttner, G., Paillet, A., Parès, L., Parot, Y., Pérez, R., Pinet, P., Poitrasson, F., Quertier, B., Sallé, B., Sotin, C., Sautter, V., Séran, H., Simmonds, J.J., Sirven, J.-B., Stiglich, R., Striebig, N., Thocaven, J.-J., Toplis, M.J., Vaniman, D., 2012. The ChemCam Instrument Suite on the Mars Science Laboratory (MSL) Rover: Science Objectives and Mast Unit Description. Space Sci. Rev. 170, 95-166. doi:10.1007/s11214-012-9912-2

McDougall, I., Harrison, T.M., 1999. Geochronology and thermochronology by the ${ }^{40} \mathrm{Ar} /{ }^{39} \mathrm{Ar}$ method, Oxford University Press.

McSween, H.Y., Arvidson, R.E., Bell, J.F., Blaney, D., Cabrol, N.A., Christensen, P.R., Clark, B.C., Crisp, J.A., Crumpler, L.S., Des Marais, D.J., Farmer, J.D., Gellert, R., Ghosh, A., Gorevan, S., Graff, T., Grant, J., Haskin, L.A., Herkenhoff, K.E., Johnson, J.R., Jolliff, B.L., Klingelhoefer, G., Knudson, A.T., McLennan, S., Milam, K.A., Moersch, J.E., Morris, R. V, Rieder, R., Ruff, S.W., de Souza, P.A., Squyres, S.W., Wänke, H., Wang, A., Wyatt, M.B., Yen, A., Zipfel, J., 2004. Basaltic Rocks Analyzed by the Spirit Rover in Gusev Crater. Science 305, 842-845. doi:10.1126/science. 3050842

Melleton, J., Gloaguen, E., Frei, D., Lima, A., 2011. U-Pb dating of columbite-tantalite from Variscan rare-elements granites and pegmatites, in: Goldschmidt Conference. Praque, Czech Republic, p. 1452.

Mermet, J.M., 2008. Limit of quantitation in atomic spectrometry: An unambiguous concept? Spectrochim. Acta - Part B At. Spectrosc. 63, 166-182. doi:10.1016/j.sab.2007.11.029

Morgan, L.E., Munk, M., Davidheiser-Kroll, B., Warner, N.H., Gupta, S., Slaybaugh, R., Harkness, P., Mark, D.F., 2017. Instrumentation Development for In Situ 40 Ar/ 39 Ar Planetary Geochronology. Geostand. Geoanalytical Res. 41, 381-396. doi:10.1111/ggr.12170

Morris, R. V., Vaniman, D.T., Blake, D.F., Gellert, R., Chipera, S.J., Rampe, E.B., Ming, D.W., Morrison, S.M., Downs, R.T., Treiman, A.H., Yen, A.S., Grotzinger, J.P., Achilles, C.N., Bristow, T.F., Crisp, J.A., Des Marais, D.J., Farmer, J.D., Fendrich, K. V., Frydenvang, J., Graff, T.G., Morookian, J.M., Stolper, E.M., Schwenzer, S.P., Blundy, J., Hazen, R.M., Mcsween, H.Y., 2016. Silicic volcanism on Mars evidenced by tridymite in high-SiO 2 sedimentary rock at Gale crater. Proc. Natl. Acad. Sci. 113, 7071-7076. doi:10.1073/pnas.1607098113

Mosier-Boss, P.A., Lieberman, S.H., Theriault, G.A., 2002. Field Demonstrations of a Direct Push FO-LIBS Metal Sensor. Environ. Sci. Technol. 36, 3968-3976. doi:10.1021/es020528z

NIST atomic spectra electronic database [WWW Document], n.d. URL http://physics.nist.gov/ PhysRefData/ASD/index.html 
Odin, G.S., et al., 1982. Interlaboratory Standards for Dating Purposes, in: G. S. Odin, Ed., Numerical Dating in Stratigraphy, Part 1. John Wiley \& Sons, Chichester, pp. 123-148.

Palucis, M.C., Dietrich, W.E., Hayes, A.G., Williams, R.M.E., Calef, F., Sumner, D.Y., Gupta, S., Hardgrove, C.J., MSL Science Team, 2013. Origin and Evolution of the Peace Vallis Fan System that Drains into the Curiosity Landing Area, Gale Crater, in: 44th Lunar and Planetary Science Conference. The Woodlands, Texas, p. 1607.

Payré, V., Fabre, C., Cousin, A., Sautter, V., Wiens, R.C., Forni, O., Gasnault, O., Mangold, N., Meslin, P.-Y., Lasue, J., Ollila, A., Rapin, W., Maurice, S., Nachon, M., Le Deit, L., Lanza, N., Clegg, S., 2017. Alkali trace elements in Gale crater, Mars, with ChemCam: Calibration update and geological implications. J. Geophys. Res. Planets 122, 650-679. doi:10.1002/2016JE005201

Perez, R., Barraclough, B.L., Bender, S.C., Cousin, A., Cros, A., DeFlores, L., LeRoch, N., Maurice, S., Paillet, A., Pares, L., Parot, Y., Saccoccio, M., Wiens, R.C., 2011. The ChemCam instrument for the 2011 Mars Science Laboratory Mission: System Requirements and Performance, in: 8th International Planetary Probe Workshop. Portsmouth, pp. 6-10.

Quidelleur, X., Gillot, P.-Y., Soler, V., Lefèvre, J.-C., 2001. K/Ar dating extended into the last millennium: Application to the youngest effusive episode of the Teide Volcano (Spain). Geophys. Res. Lett. 28, 3067-3070. doi:10.1029/2000GL012821

Renne, P.R., Mundil, R., Balco, G., Min, K., Ludwig, K.R., 2010. Joint determination of 40K decay constants and $40 \mathrm{Ar} * / 40 \mathrm{~K}$ for the Fish Canyon sanidine standard, and improved accuracy for 40Ar/39Ar geochronology. Geochim. Cosmochim. Acta 74, 5349-5367. doi:10.1016/j.gca.2010.06.017

Ricci, J., Quidelleur, X., Pavlov, V., Orlov, S., Shatsillo, A., Courtillot, V., 2013. New 40 Ar / 39 Ar and $\mathrm{K}-\mathrm{Ar}$ ages of the Viluy traps ( Eastern Siberia ): Further evidence for a relationship with the Frasnian - Famennian mass extinction. Palaeogeogr. Palaeoclimatol. Palaeoecol. 386, 531540. doi:10.1016/j.palaeo.2013.06.020

Riedo, A., Meyer, S., Heredia, B., Neuland, M.B., Bieler, A., Tulej, M., Leya, I., Iakovleva, M., Mezger, K., Wurz, P., 2013. Highly accurate isotope composition measurements by a miniature laser ablation mass spectrometer designed for in situ investigations on planetary surfaces. Planet. Space Sci. 87, 1-13. doi:10.1016/j.pss.2013.09.007

Rouchon, V., Lefèvre, J.C., Quidelleur, X., Guérin, G., Gillot, P.Y., 2008. Nonspiked 40Ar and 36Ar quantification using a quadrupole mass spectrometer: A potential for K-Ar geochronology. Int. J. Mass Spectrom. 270, 52-61. doi:10.1016/j.ijms.2007.11.009

Sagna, I., Quidelleur, X., Ndiaye, F., Gillot, P.-Y., Lefevre, J.-C., Dioh, E., 2017. K-Ar mineral ages and thermal history of magmatic and metamorphic Palaeoproterozoic units from the northern part of Kedougou Kenieba Inlier, West African Craton (Eastern Senegal). Geol. J. 52, 207-216. doi:10.1002/gj.2749

Sallé, B., Lacour, J.L., Mauchien, P., Fichet, P., Maurice, S., Manhès, G., 2006. Comparative study of different methodologies for quantitative rock analysis by Laser-Induced Breakdown Spectroscopy in a simulated Martian atmosphere. Spectrochim. Acta Part B At. Spectrosc. 61, 301-313. doi:10.1016/J.SAB.2006.02.003

Sautter, V., Fabre, C., Forni, O., Toplis, M.J., Cousin, A., Ollila, A.M., Meslin, P.Y., Maurice, S., Wiens, R.C., Baratoux, D., Mangold, N., Le Mouélic, S., Gasnault, O., Berger, G., Lasue, J., Anderson, R.A., Lewin, E., Schmidt, M., Dyar, D., Ehlmann, B.L., Bridges, J., Clark, B., Pinet, P., 2014. Igneous mineralogy at bradbury rise: The first chemcam campaign at gale crater. J. 
Geophys. Res. E Planets 119, 30-46. doi:10.1002/2013JE004472

Schneider, B., Kuiper, K., Postma, O., Wijbrans, J., 2009. 40Ar/39Ar geochronology using a quadrupole mass spectrometer. Quat. Geochronol. 4, 508-516.

doi:10.1016/j.quageo.2009.08.003

Solé, J., 2014. In situ determination of K-Ar ages from minerals and rocks using simultaneous laserinduced plasma spectroscopy and noble gas mass spectrometry. Chem. Geol. 388, 9-22. doi:10.1016/j.chemgeo.2014.08.027

Steiger, R.H., Jager, E., 1977. Subcommission on geochronology: convention on the use of decay constants in geo-and cosmochronology. Earth Planet. Sctence Lett. 36, 359-362. doi:10.1016/0012-821X(77)90060-7

Stipe, C.B., Guevara, E., Brown, J., Rossman, G.R., 2012. Quantitative laser-induced breakdown spectroscopy of potassium for in-situ geochronology on Mars. Spectrochim. Acta - Part B At. Spectrosc. 70, 45-50. doi:10.1016/j.sab.2012.04.010

Talboys, D.L., Barber, S., Bridges, J.C., Kelley, S.P., Pullan, D., Verchovsky, A.B., Butcher, G., Fazel, A., Fraser, G.W., Pillinger, C.T., Sims, M.R., Wright, I.P., 2009. In situ radiometric dating on Mars: Investigation of the feasibility of K-Ar dating using flight-type mass and X-ray spectrometers. Planet. Space Sci. 57, 1237-1245. doi:10.1016/j.pss.2009.02.012

Tucker, J., 2009. Calibrating ChemCam: Preparing to Probe the Red Planet. Amherst College.

Tucker, J.M., Dyar, M.D., Schaefer, M.W., Clegg, S.M., Wiens, R.C., 2010. Optimization of laserinduced breakdown spectroscopy for rapid geochemical analysis. Chem. Geol. 277, 137-148. doi:10.1016/J.CHEMGEO.2010.07.016

Vaniman, D.T., Bish, D.L., Ming, D.W., Bristow, T.F., Morris, R. V., Blake, D.F., Chipera, S.J., Morrison, S.M., Treiman, A.H., Rampe, E.B., Rice, M., Achilles, C.N., Grotzinger, J.P., McLennan, S.M., Williams, J., Bell, J.F., Newsom, H.E., Downs, R.T., Maurice, S., Sarrazin, P., Yen, A.S., Morookian, J.M., Farmer, J.D., Stack, K., Milliken, R.E., Ehlmann, B.L., Sumner, D.Y., Berger, G., Crisp, J.A., Hurowitz, J.A., Anderson, R., Des Marais, D.J., Stolper, E.M., Edgett, K.S., Gupta, S., Spanovich, N., MSL Science Team, 2014. Mineralogy of a Mudstone at Yellowknife Bay, Gale Crater, Mars. Science 343, 1243480-1243480. doi:10.1126/science. 1243480

Wiens, R.C., Maurice, S., Barraclough, B., Saccoccio, M., Barkley, W.C., Bell, J.F., Bender, S., Bernardin, J., Blaney, D., Blank, J., Bouyé, M., Bridges, N., Bultman, N., Caïs, P., Clanton, R.C., Clark, B., Clegg, S., Cousin, A., Cremers, D., Cros, A., Deflores, L., Delapp, D., Dingler, R., D'Uston, C., Dyar, M.D., Elliott, T., Enemark, D., Fabre, C., Flores, M., Forni, O., Gasnault, O., Hale, T., Hays, C., Herkenhoff, K., Kan, E., Kirkland, L., Kouach, D., Landis, D., Langevin, Y., Lanza, N., Larocca, F., Lasue, J., Latino, J., Limonadi, D., Lindensmith, C., Little, C., Mangold, N., Manhes, G., Mauchien, P., McKay, C., Miller, E., Mooney, J., Morris, R. V., Morrison, L., Nelson, T., Newsom, H., Ollila, A., Ott, M., Pares, L., Perez, R., Poitrasson, F., Provost, C., Reiter, J.W., Roberts, T., Romero, F., Sautter, V., Salazar, S., Simmonds, J.J., Stiglich, R., Storms, S., Striebig, N., Thocaven, J.J., Trujillo, T., Ulibarri, M., Vaniman, D., Warner, N., Waterbury, R., Whitaker, R., Witt, J., Wong-Swanson, B., 2012. The ChemCam instrument suite on the Mars Science Laboratory (MSL) rover: Body unit and combined system tests. Space Sci. Rev. 170, 167-227. doi:10.1007/s11214-012-9902-4

Wiens, R.C., Maurice, S., Lasue, J., Forni, O., Anderson, R.B., Clegg, S., Bender, S., Blaney, D., Barraclough, B.L., Cousin, A., Deflores, L., Delapp, D., Dyar, M.D., Fabre, C., Gasnault, O., Lanza, N., Mazoyer, J., Melikechi, N., Meslin, P.Y., Newsom, H., Ollila, A., Perez, R., Tokar, 
R.L., Vaniman, D., 2013. Pre-flight calibration and initial data processing for the ChemCam laser-induced breakdown spectroscopy instrument on the Mars Science Laboratory rover. Spectrochim. Acta - Part B At. Spectrosc. 82, 1-27. doi:10.1016/j.sab.2013.02.003

Williams, R.M.E., Grotzinger, J.P., Dietrich, W.E., Gupta, S., Sumner, D.Y., Wiens, R.C., Mangold, N., Malin, M.C., Edgett, K.S., Maurice, S., Forni, O., Gasnault, O., Ollila, A., Newsom, H.E., Dromart, G., Palucis, M.C., Yingst, R.A., Anderson, R.B., Herkenhoff, K.E., Le Mouelic, S., Goetz, W., Madsen, M.B., Koefoed, A., Jensen, J.K., Bridges, J.C., Schwenzer, S.P., Lewis, K.W., Stack, K.M., Rubin, D., Kah, L.C., Bell, J.F., Farmer, J.D., Sullivan, R., Van Beek, T., Blaney, D.L., Pariser, O., Deen, R.G., MSL Science Team, 2013. Martian Fluvial Conglomerates at Gale Crater. Science 340, 1068-1072. doi:10.1126/science.1237317

Witze, A., 2014. NASA plans Mars sample-return rover. Nature 509, 272-272. doi:10.1038/509272a 


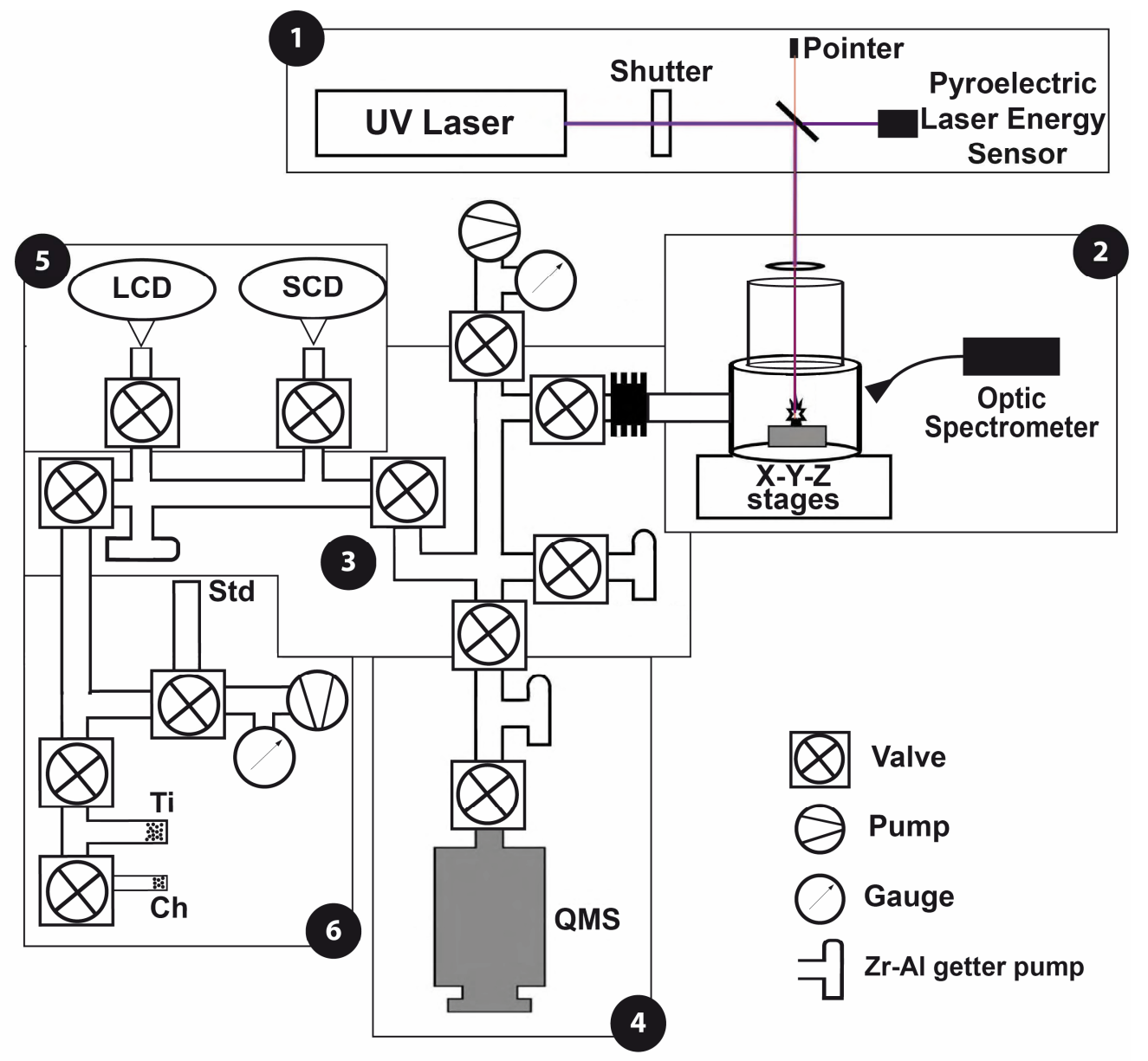

Fig. 1: Schematic diagram of the experimental setup. 1. UV laser unit and pyroelectric laser energy sensor; 2. ablation unit; 3. purification unit; 4. quadrupole mass spectrometer unit (QMS); 5. pipette unit (a known amount of atmospheric argon to calibrate the QMS detectors); LCD: large air pipette to calibrate the faraday cup; SCD: small air pipette to calibrate the electron multiplier (SEM); 6. standard calibration unit. Ti: titanium foam to purify; Ch: active charcoal to trap; Std: extraction of argon from standard samples for pipette unit calibration. 


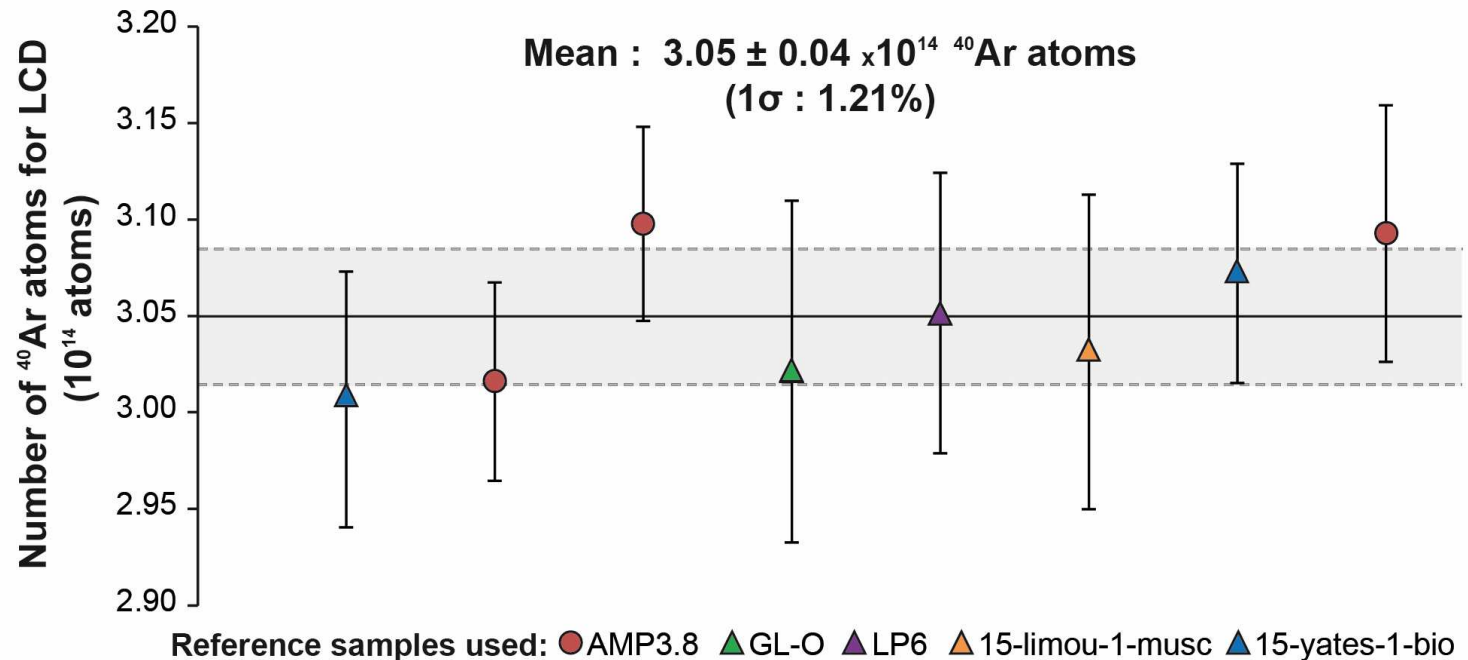

Fig. 2: Determination of number of ${ }^{40} \mathrm{Ar}$ atoms of a large air pipette (uncertainties on standard age and of measurements are integrated). This determination was calibrated by standard and reference samples with a known number of ${ }^{40} \mathrm{Ar}$ atoms per gram. i.e. GL-O (Odin and et al., 1982), LP6 (Odin and et al., 1982), AMP3.8 (David et al., 2009, and this study), 15-limou-1musc (Melleton et al., 2011, and this study) and 15-yates-1-bio (Barfod et al., 2005, and this study). 


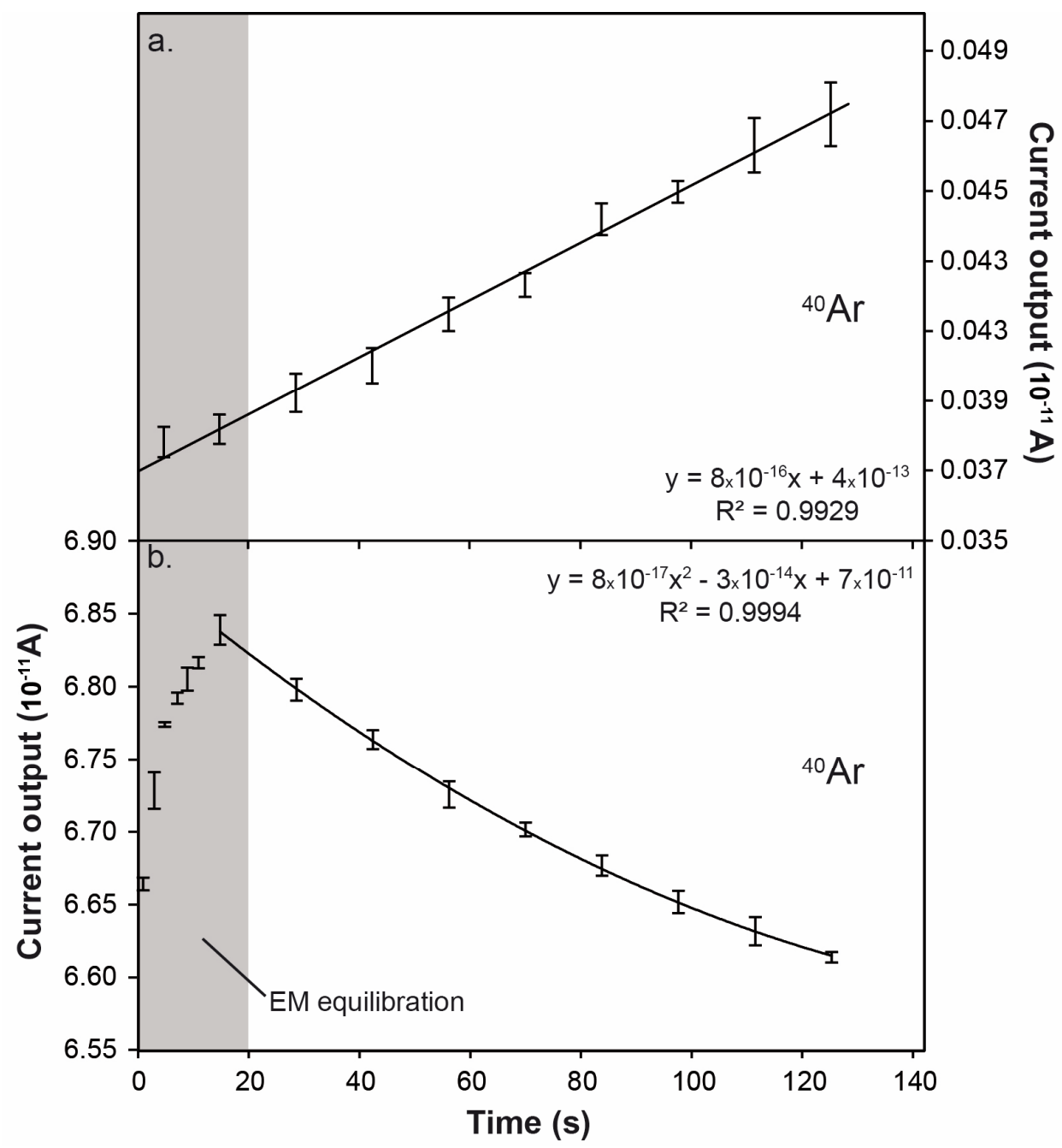

Fig. 3: Mass spectrometer signal evolution with time as a function of (a) degassing of ${ }^{40} \mathrm{Ar}$ during a line blank measurement; and (b) During the first $20 \mathrm{~s}$, signal ${ }^{40} \mathrm{Ar}$ increase due to EM equilibration (grey band), then signal of ${ }^{40} \mathrm{Ar}$ decrease due to ion implantation on the QMS during sample measurement. All signal values are SEM outputs. For each point, ${ }^{40} \mathrm{Ar}$ is determined by averaging $14 \mathrm{~s}$ of continuous SEM output. Error bars represent $1 \sigma$ uncertainties of the SEM output during this measurement time. 


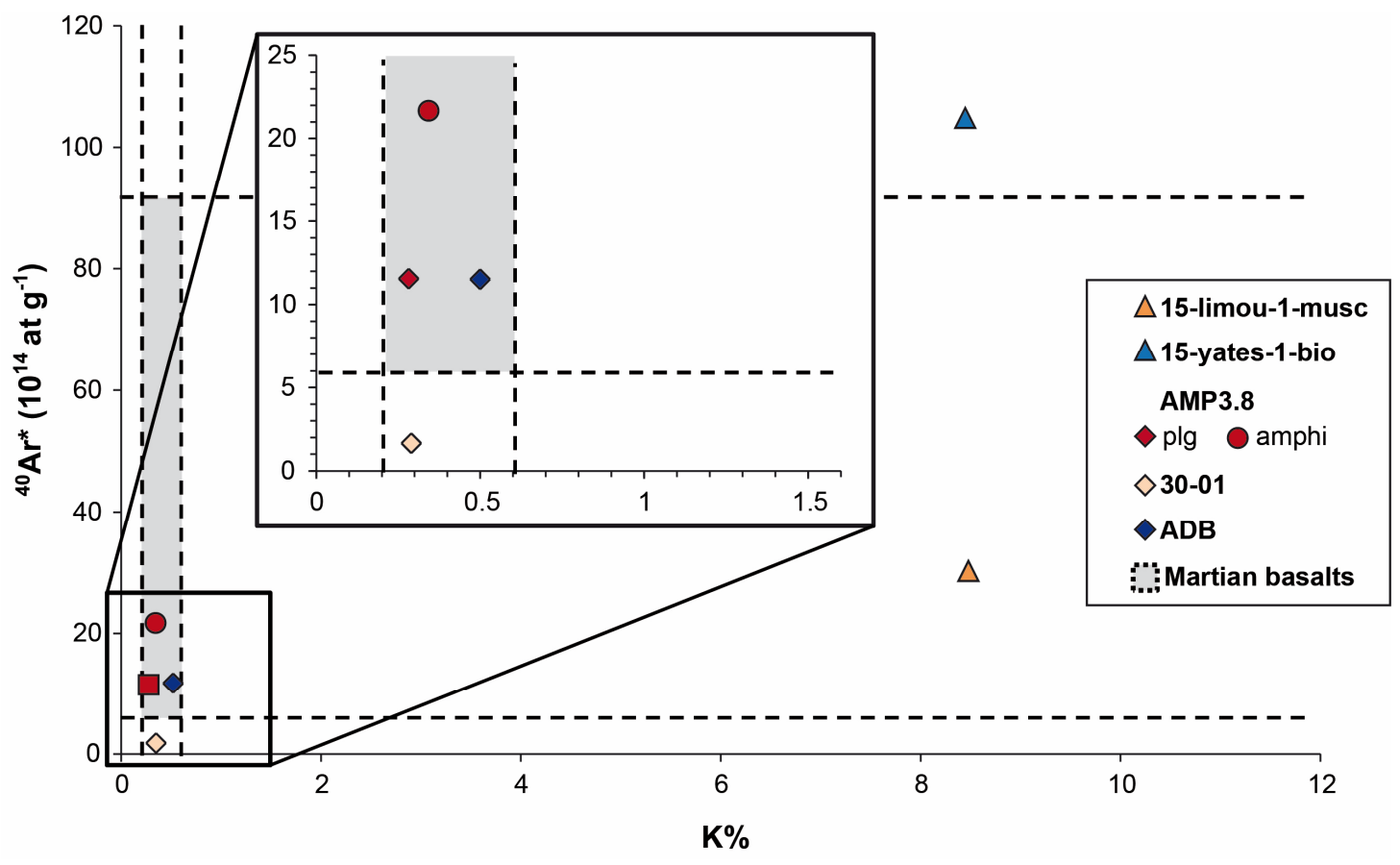

Fig. 4: Number of Ar atoms per gram versus $\mathrm{K} \%$ for reference samples. The grey bar represents expected Martian values (Bibring et al., 2006; Boynton et al., 2007). 


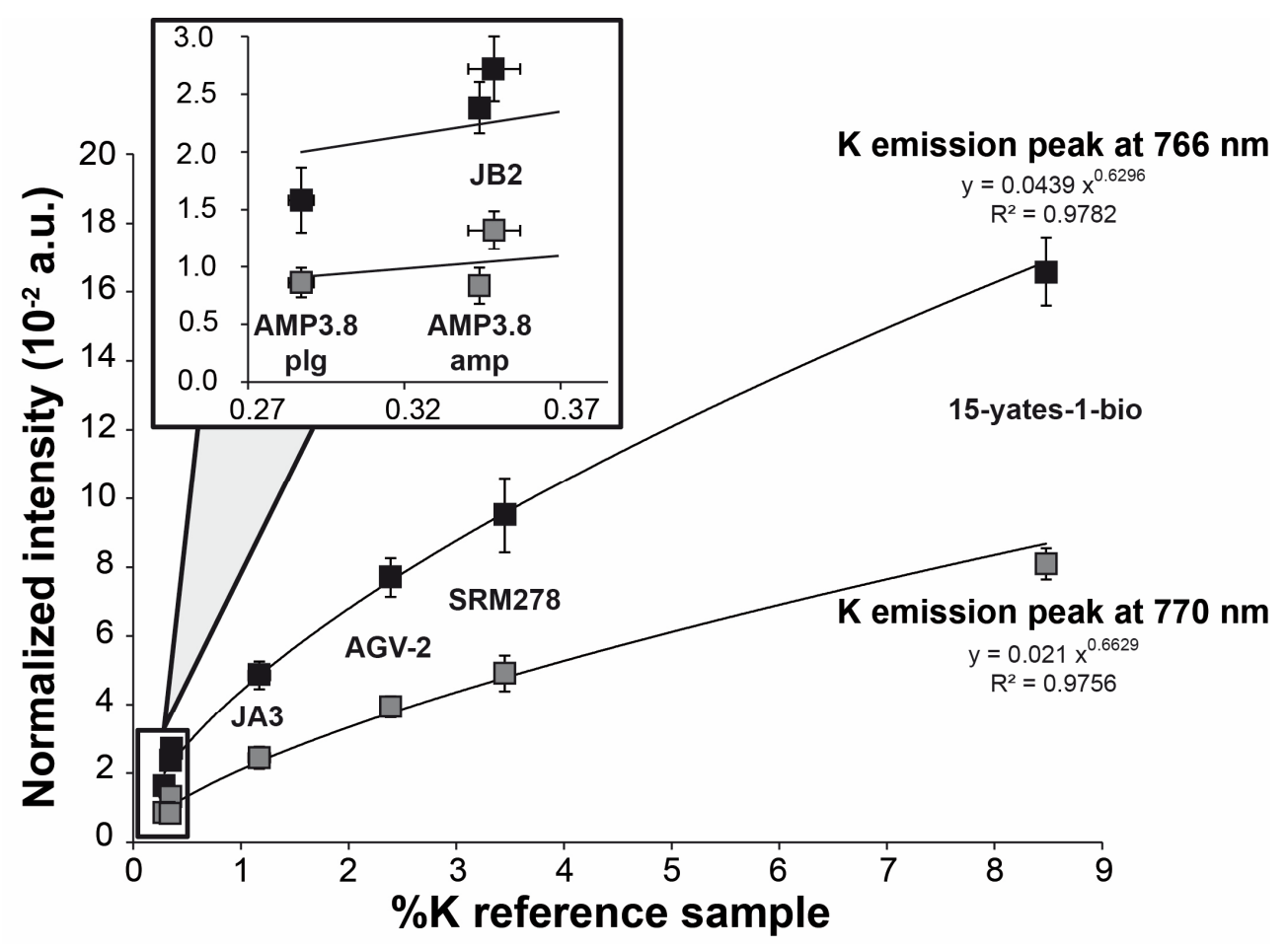

Fig. 5: Calibration curves for the potassium doublet at $766 \mathrm{~nm}$ and $770 \mathrm{~nm}$ under high vacuum conditions $\left(10^{-8} \mathrm{mbar}\right)$. The horizontal error bars indicate the standard deviations for the inter-laboratory measurements of references samples (AIST, USGS and this study), while the vertical error bars represent the standard deviations of more than ten LIBS spectra measurements of the same sample. 

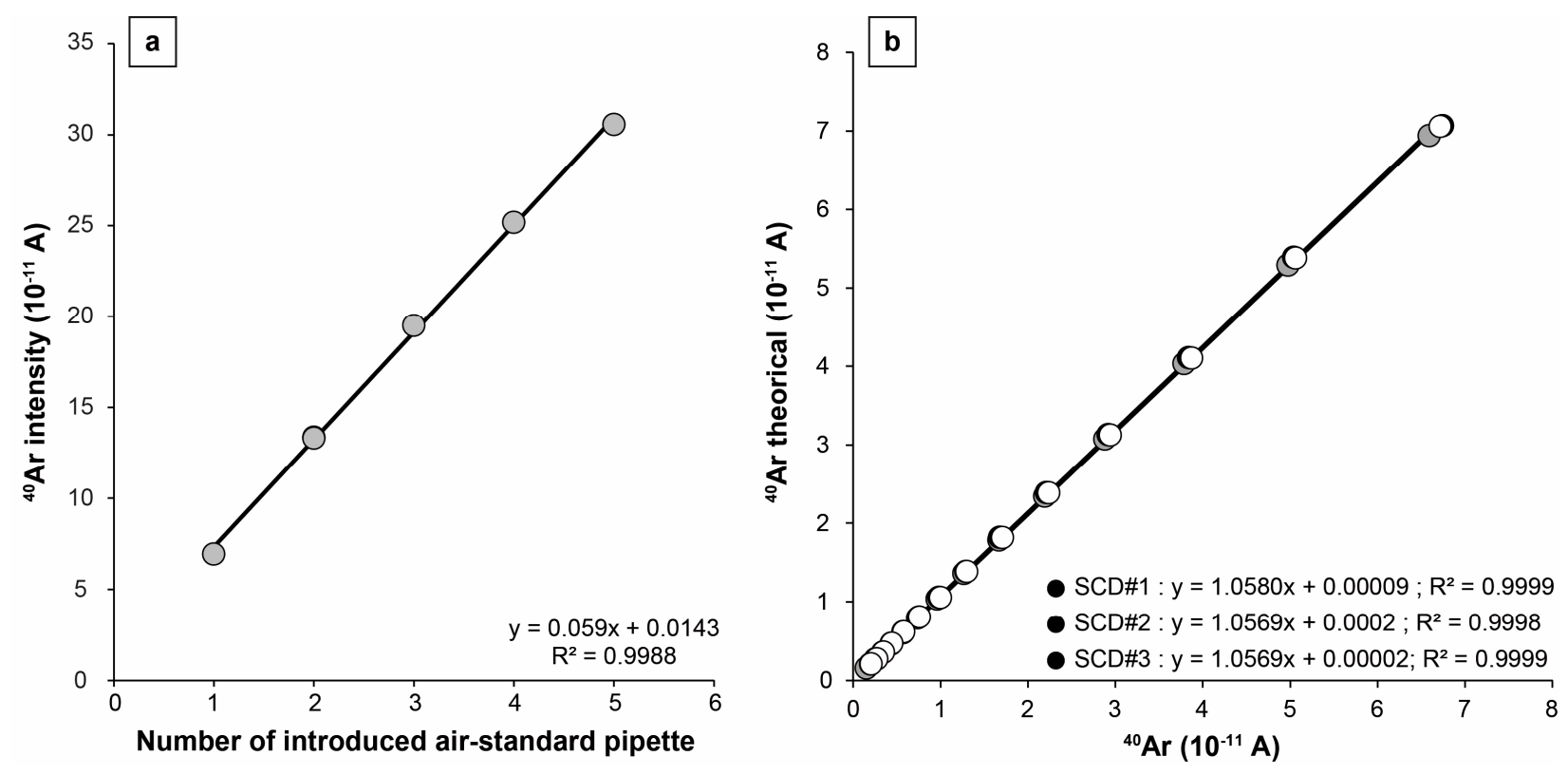

Fig. 6: QMS linearity, at low intensity values, is highlighted by (a) linear regression obtained from successive introducing of air pipettes (SCD analyses); (b) comparison between data obtained by successive decrements of 3 SCD during a conventional experiment and values calculated from theoretical modelling of a perfect decrement. Intensity measured (in $10^{-11} \mathrm{~A}$ ) decreases linearly with the number of decrement. Uncertainty of each point is less than $1 \%$ and is integrated in graphic representation. 

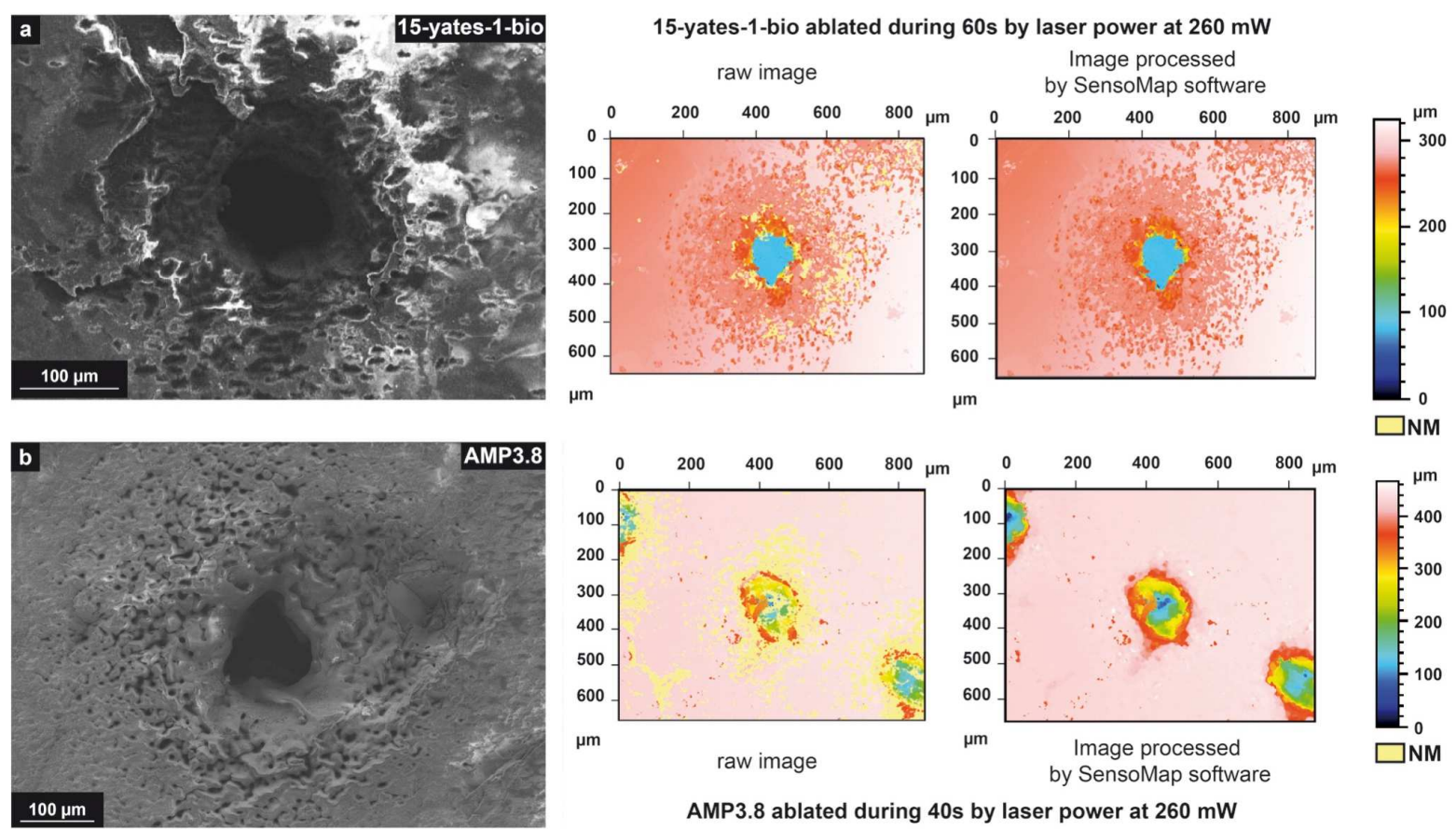

AMP3.8 ablated during 40 s by laser power at $260 \mathrm{~mW}$

Fig. 7: SEM image (right), raw and processed images from profilometry measurement (left) of ablation craters. (a) Images of a crater formed following a 60s long UV-laser ablation on phlogopite 15-yates-1-bio; (b) Image of a crater formed following a 40s long UV-laser ablation on amphibolite AMP3.8. This highlights the rough morphology of craters. The lack of observations by the profilometer is represented by NM (no measurement) on pale yellow. 


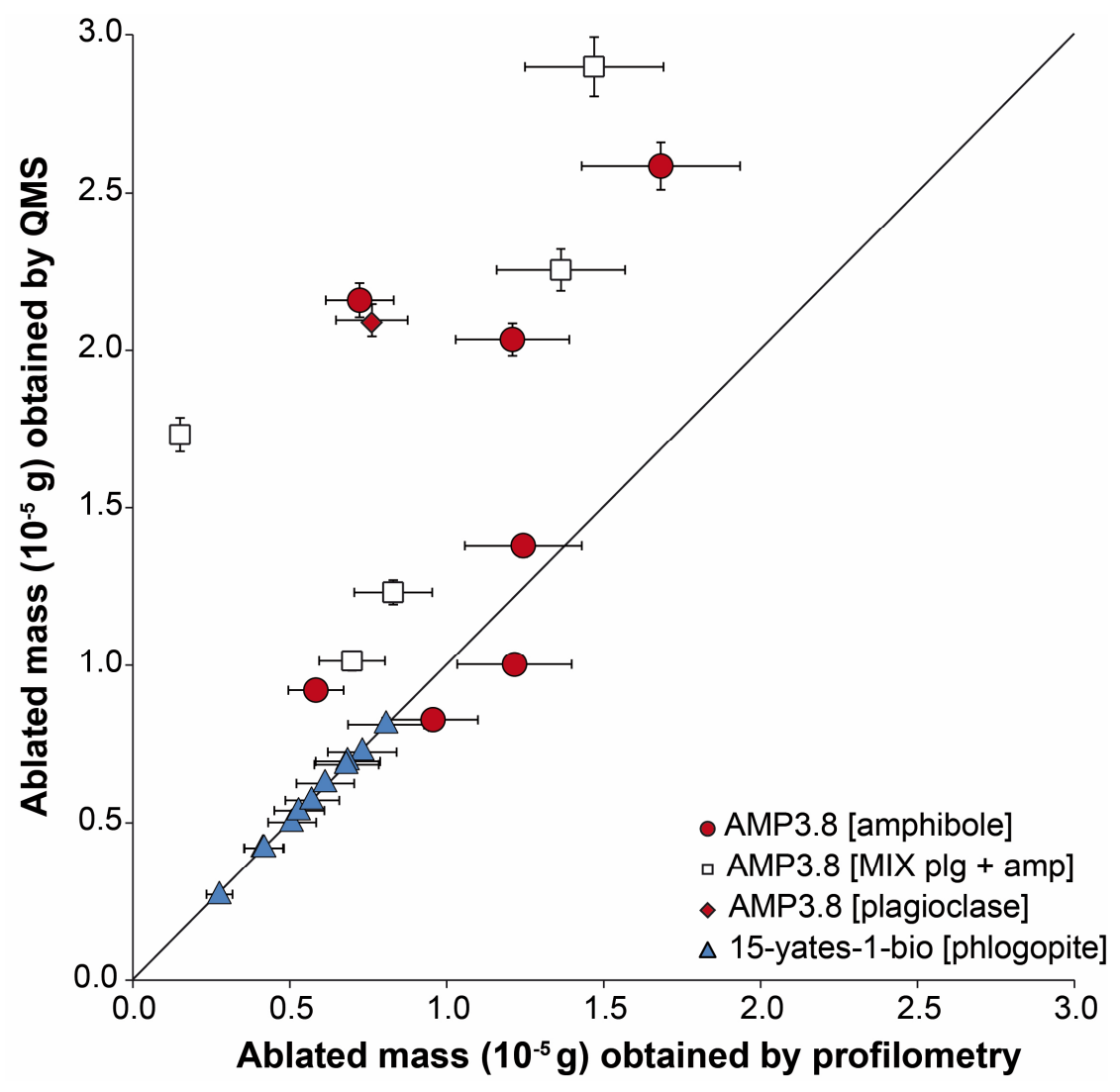

Fig. 8: Comparison between masses deduced from QMS measurements and those obtained by profilometry on 15-yates-1-bio and AMP3.8. 


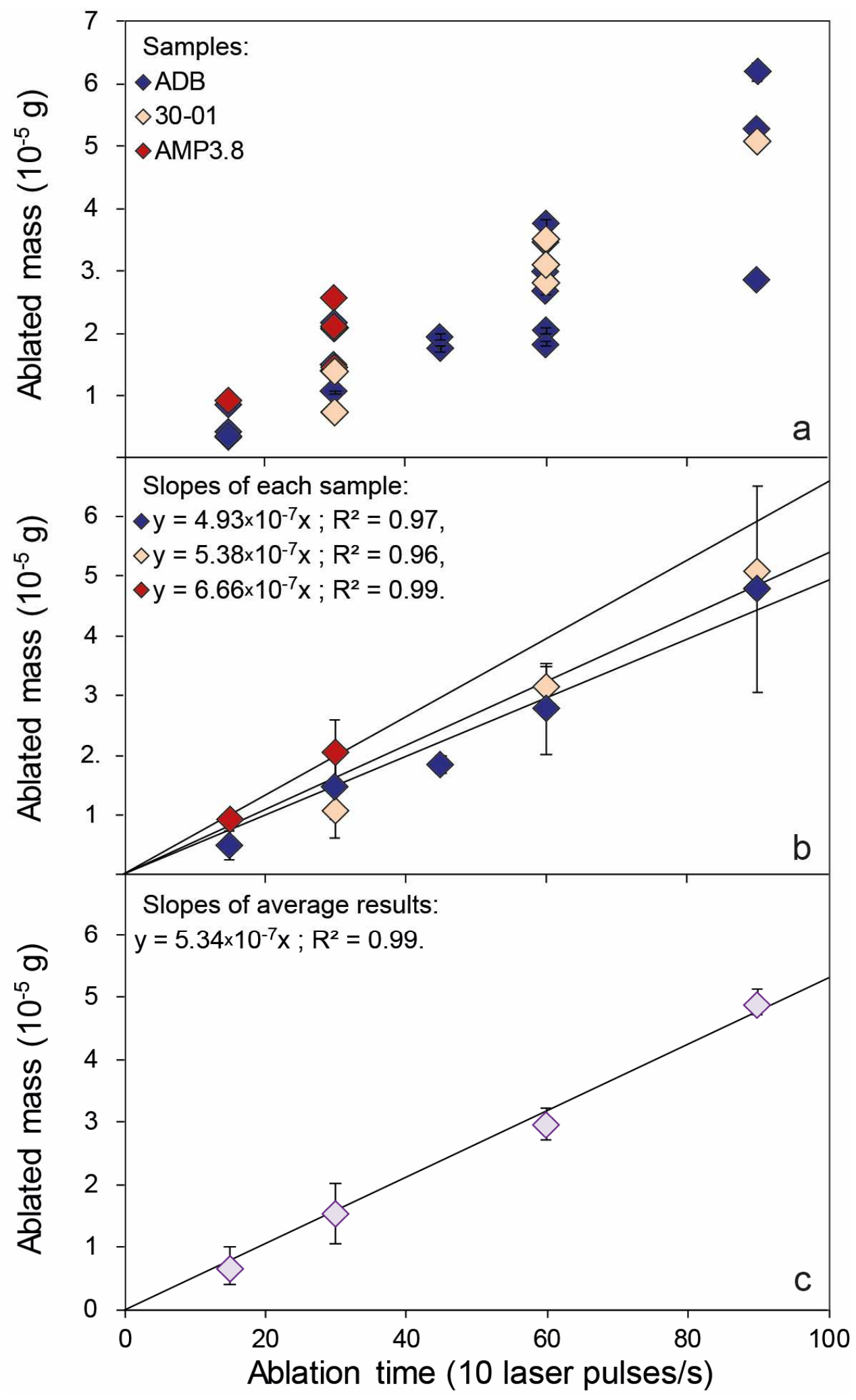

Fig. 9: Results on plagioclase ablations. (a) Ablated mass versus ablation time for plagioclase ablations from reference samples. (b) Linear regression lines obtain from mass average as a function of ablation time for each sample. (c) Correlation line between the ablated mass obtained via QMS data and the ablation time, defined from average of ablated mass defined from plagioclase minerals of reference sample. 

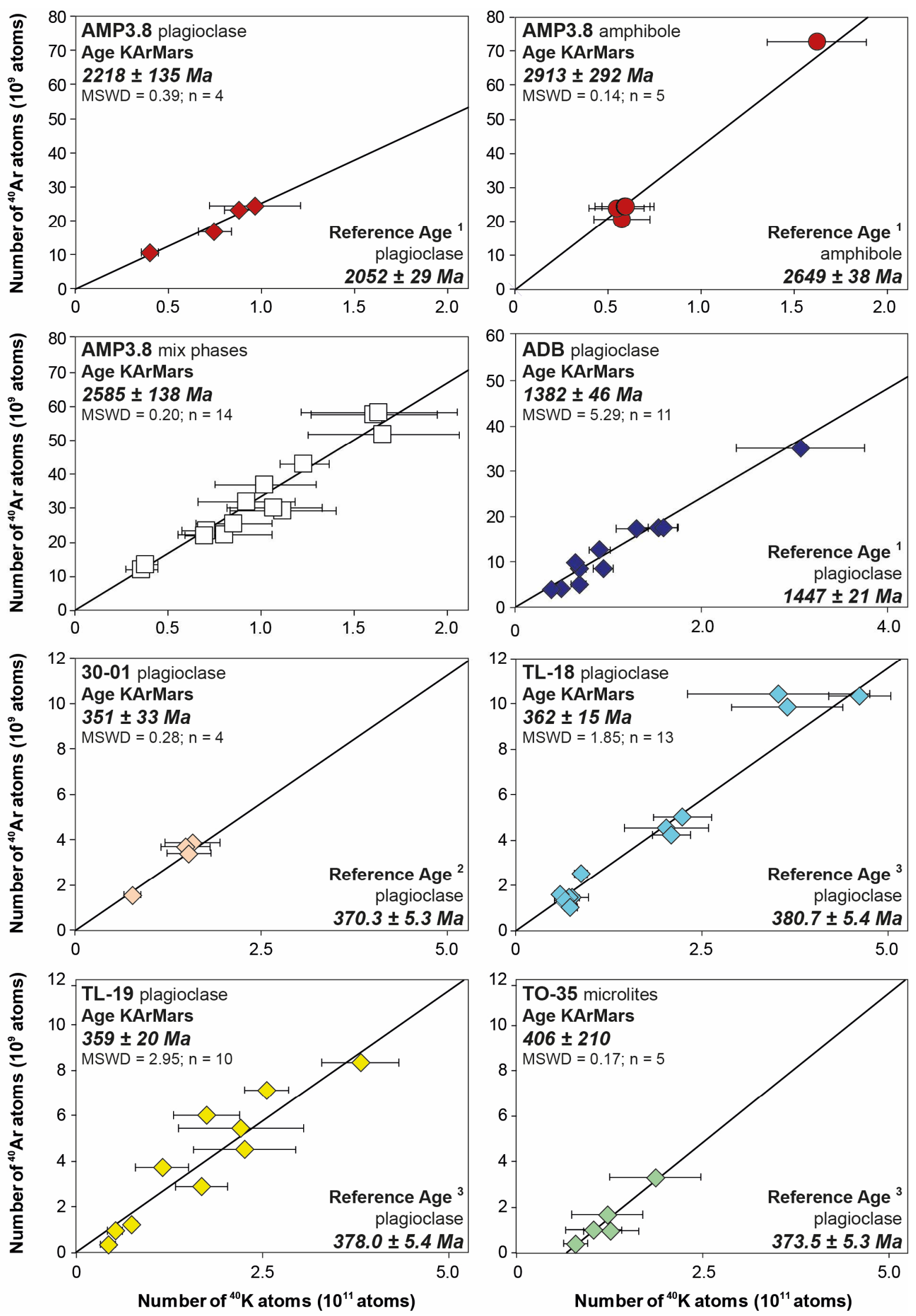

Fig. 10: KArMars results obtained on Nuvvuagittuq amphibolite (AMP3.8), Churchill province enderbite (ADB) and Viluy basalts (30-01, TL-18, TL-19, TO-35) used as unknown samples (1: this work; 2: Courtillot et al., 2010; 3: Ricci et al., 2013). 


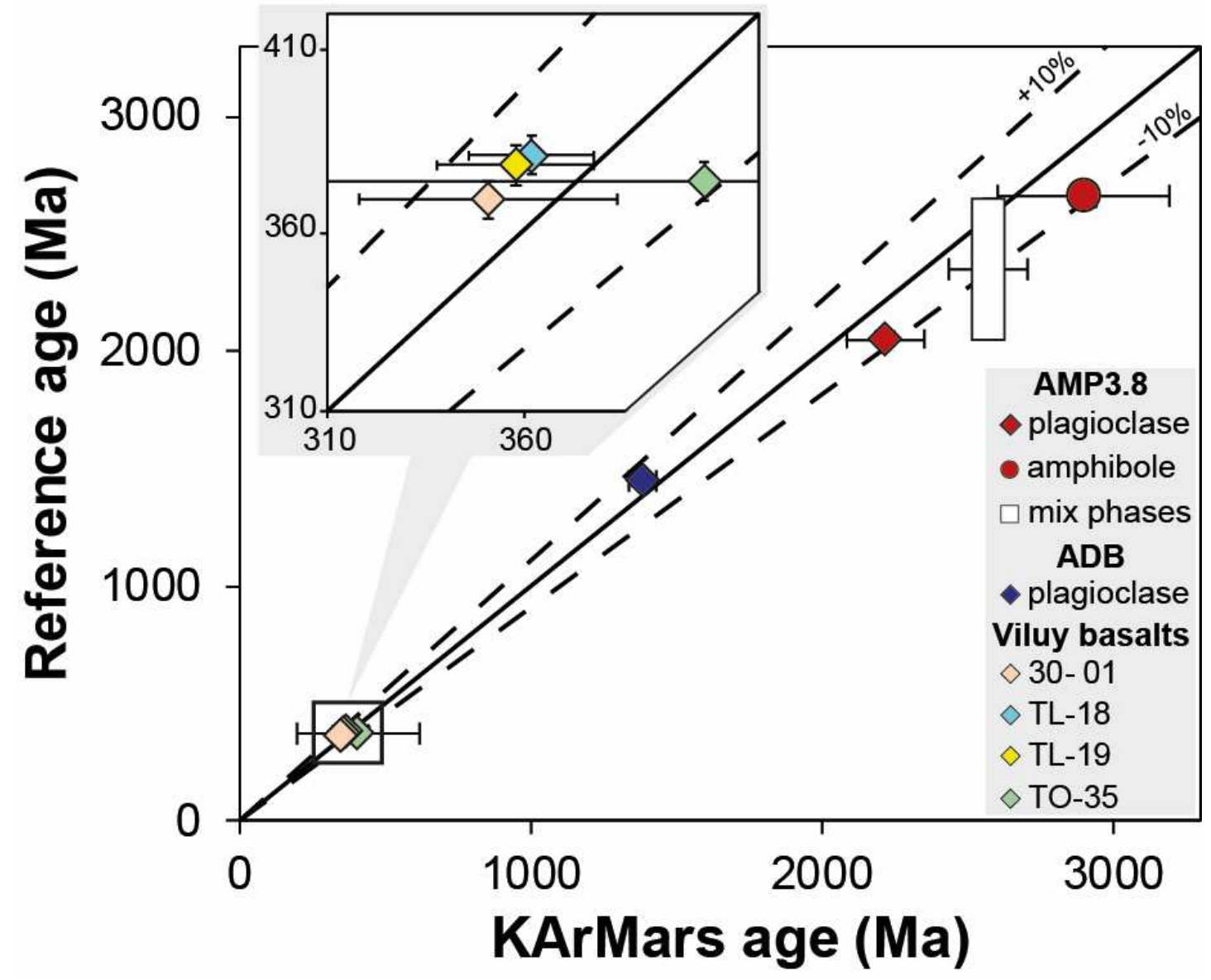

Fig. 11: Comparison between reference and KArMars ages on AMP3.8, ADB and Viluy basalts. 
Table 1: Data obtained in previous studies on samples selected here for calibration.

\begin{tabular}{|c|c|c|c|c|c|c|}
\hline Locality & Sample name & $\begin{array}{c}\text { Position } \\
\text { (WGS84) }\end{array}$ & $\begin{array}{l}\text { Age } \pm 1 \sigma \\
(\mathrm{Ma})\end{array}$ & Method & $\begin{array}{l}\text { Analyzed } \\
\text { phase }\end{array}$ & Ref. \\
\hline \multirow{2}{*}{ Otter lake (Quebec) } & \multirow{2}{*}{$\begin{array}{c}\text { 15-yates-1-bio } \\
\text { (phlogopite) }\end{array}$} & \multirow{2}{*}{$\begin{array}{l}45^{\circ} 57^{\prime} 50^{\prime \prime} \mathrm{N} \\
76^{\circ} 32^{\prime} 27^{\prime \prime} \mathrm{W} \\
\end{array}$} & \multirow{2}{*}{$\begin{array}{c}913 \pm 7 \\
1002 \pm 7\end{array}$} & \multirow{2}{*}{$\begin{array}{l}\mathrm{U}-\mathrm{Pb} \\
\mathrm{U}-\mathrm{Pb}\end{array}$} & \multirow{2}{*}{$\begin{array}{l}\text { Apatite } \\
\text { Titanite } \\
\end{array}$} & (Barfod et al., 2005) \\
\hline & & & & & & (Frei et al., 1997) \\
\hline Limousin & $\begin{array}{l}\text { 15-limou-1-musc } \\
\text { (muscovite) }\end{array}$ & $\begin{array}{c}45^{\circ} 56^{\prime} 07.2^{\prime \prime} \mathrm{N} \\
1^{\circ} 23^{\prime} 47.0^{\prime \prime} \mathrm{E}\end{array}$ & $\begin{array}{l}309 \pm 1 \\
309 \pm 5\end{array}$ & $\begin{array}{c}{ }^{40} \mathrm{Ar} /{ }^{39} \mathrm{Ar} \\
\mathrm{U}-\mathrm{Pb}\end{array}$ & $\begin{array}{l}\text { Lepidolite } \\
\text { Oxide }\end{array}$ & $\begin{array}{l}\text { (Cheilletz et al., 1992; } \\
\text { Melleton et al., 2011) }\end{array}$ \\
\hline $\begin{array}{c}\text { Nuvvuagittuq } \\
\text { (Quebec) }\end{array}$ & $\begin{array}{c}\text { AMP3.8 } \\
\text { (amphibolite) }\end{array}$ & $\begin{array}{l}58^{\circ} 17^{\prime} 18^{\prime \prime} \mathrm{N} \\
77^{\circ} 36^{\prime} 42^{\prime \prime} \mathrm{W}\end{array}$ & $\begin{array}{c}2693 \pm 3 \\
2400 \pm 200\end{array}$ & $\begin{array}{l}\mathrm{U}-\mathrm{Pb} \\
\mathrm{U}-\mathrm{Pb}\end{array}$ & $\begin{array}{c}\text { Zircon } \\
\text { Whole-rock }\end{array}$ & $\begin{array}{l}\text { (David et al., 2009; } \\
\text { O'Neil et al., 2008) }\end{array}$ \\
\hline $\begin{array}{c}\text { Churchill province } \\
\text { (Quebec) }\end{array}$ & $\begin{array}{c}\text { ADB } \\
\text { (enderbite) }\end{array}$ & $\begin{array}{l}56^{\circ} 57^{\prime} 37^{\prime \prime N} \\
64^{\circ} 21^{\prime} 19^{\prime \prime} \mathrm{W} \\
\end{array}$ & $1860 \pm 15$ & $\mathrm{U}-\mathrm{Pb}$ & Zircon & (Davis et al., 2018) \\
\hline $\begin{array}{c}\text { Siberia } \\
\text { (Viluy river) }\end{array}$ & $\begin{array}{c}30-01 \\
\text { (dolerite) }\end{array}$ & $\begin{array}{c}64^{\circ} 4^{\prime} 18^{\prime \prime} \mathrm{N} \\
116^{\circ} 18^{\prime} 56^{\prime \prime} \mathrm{E}\end{array}$ & $\begin{array}{l}370.3 \pm 5.3 \\
370.4 \pm 2.0\end{array}$ & $\begin{array}{c}\mathrm{K}-\mathrm{Ar} \\
{ }^{40} \mathrm{Ar} /{ }^{39} \mathrm{Ar}\end{array}$ & Plagioclase & (Courtillot et al., 2010) \\
\hline
\end{tabular}


Table 2: Concentration of $\mathrm{K}$ present in K-bearing phases and whole rock of reference samples. The number of measurement spots performed by EPMA is listed for minerals found in each sample (n).

\begin{tabular}{|c|c|c|c|c|}
\hline Sample name & $\begin{array}{c}\text { Analyzed } \\
\text { phase }\end{array}$ & Method & $\begin{array}{c}\text { K content } \pm \\
\text { un. (wt.\%) }\end{array}$ & n \\
\hline 15-yates-1-bio & Phlogopite & ICP-OES & $8.41 \pm 0.42$ & \\
\cline { 3 - 5 } & & EPMA & $8.54 \pm 0.21$ & 80 \\
\hline \multirow{2}{*}{ 15-limou-1-musc } & Muscovite & ICP-OES & $8.49 \pm 0.42$ & \\
\cline { 3 - 5 } & EPMA & $8.74 \pm 0.42$ & 120 \\
\hline \multirow{5}{*}{ AMP3.8 } & Amphibole & ICP-OES & $0.35 \pm 0.09$ & \\
& Whole rock & & $0.39 \pm 0.10$ & \\
& Amphibole & & $0.34 \pm 0.04$ & 86 \\
& Labradorite & EPMA & $0.05 \pm 0.02$ & 19 \\
& Bytownite & & $0.04 \pm 0.02$ & 20 \\
\hline
\end{tabular}


Table 3: K-Ar ages obtained in this study.

\begin{tabular}{|c|c|c|c|c|c|c|c|}
\hline Locality & Sample name & $\begin{array}{l}\text { Analyzed } \\
\text { phase } \\
(\text { size } \mu \mathrm{m})\end{array}$ & $\underset{(w t . \%)}{K}$ & $\begin{array}{c}{ }^{40} \mathrm{Ar}^{*} \\
\left(\mathbf{x 1 0}^{14} \text { at } \mathrm{g}^{-1}\right)\end{array}$ & $\begin{array}{l}{ }^{40} \mathrm{Ar} * \\
(\%)\end{array}$ & $\begin{array}{l}\text { Age } \pm \text { un. } \\
\quad \text { (Ma) }\end{array}$ & $\begin{array}{l}\text { Mean } \pm \text { un. } \\
\text { (Ma) }\end{array}$ \\
\hline \multirow{3}{*}{$\begin{array}{l}\text { Nuvvuagittuq } \\
\text { (Quebec) }\end{array}$} & AMP3.8-15 & $\begin{array}{l}\text { Amphibole } \\
(125-250)\end{array}$ & 0.34 & $\begin{array}{l}21.69 \\
21.67\end{array}$ & $\begin{array}{l}95.8 \\
81.7\end{array}$ & $\begin{array}{l}2649.9 \pm 37.6 \\
2648.8 \pm 37.6\end{array}$ & $2649 \pm 38$ \\
\hline & AMP3.8-16 & $\begin{array}{c}\text { Plagioclase } \\
(125-250)\end{array}$ & 0.29 & $\begin{array}{l}11.50 \\
11.61 \\
\end{array}$ & $\begin{array}{l}88.1 \\
75.4\end{array}$ & $\begin{array}{l}2046.1 \pm 29.0 \\
2058.2 \pm 29.2\end{array}$ & $2052 \pm 29$ \\
\hline & $\mathrm{ADB}$ & $\begin{array}{c}\text { Plagioclase } \\
(125-250)\end{array}$ & 0.50 & $\begin{array}{l}11.77 \\
11.39\end{array}$ & $\begin{array}{l}91.9 \\
92.8\end{array}$ & $\begin{array}{l}1456.8 \pm 21.0 \\
1437.9 \pm 20.0\end{array}$ & $1447 \pm 21$ \\
\hline $\begin{array}{l}\text { Otter lake } \\
\text { (Quebec) }\end{array}$ & 15-yates-1-bio & $\begin{array}{c}\text { Phlogopite } \\
(>1000)\end{array}$ & 8.48 & $\begin{array}{l}104.3 \\
104.3\end{array}$ & $\begin{array}{l}76.7 \\
91.8\end{array}$ & $\begin{array}{l}906.2 \pm 12.9 \\
906.5 \pm 12.9\end{array}$ & $906.4 \pm 12.9$ \\
\hline Limousin & 15-limou-1-musc & $\begin{array}{c}\text { Muscovite } \\
(>1000)\end{array}$ & 8.49 & $\begin{array}{l}29.95 \\
30.07 \\
\end{array}$ & $\begin{array}{l}87.8 \\
92.6 \\
\end{array}$ & $\begin{array}{l}309.6 \pm 4.4 \\
310.8 \pm 4.4\end{array}$ & $310.2 \pm 4.4$ \\
\hline
\end{tabular}


Table 4: LIBS results on standard and reference samples used for calibration. The number of analyzed spectra is indicated on the " $\mathrm{N}$ " column. Measurements with longer ablation time were performed to highlight possible variations.

\begin{tabular}{|c|c|c|c|c|c|c|c|}
\hline \multirow[b]{2}{*}{ Sample name } & \multirow[b]{2}{*}{$\begin{array}{l}\text { Ref. K content } \\
\pm \text { un. }(\text { wt. } \%)\end{array}$} & \multicolumn{6}{|c|}{ Ablation time shorter than 15s - Data used to performed calibration curve } \\
\hline & & $\begin{array}{c}\text { A/Itot } \\
(766.49 \mathrm{~nm})\end{array}$ & $\begin{array}{c}\text { Standard } \\
\text { deviation }(\%)\end{array}$ & $\mathbf{N}$ & $\begin{array}{c}\text { A/Itot } \\
(769.89 \mathrm{~nm}) \\
\end{array}$ & $\begin{array}{c}\text { Standard } \\
\text { deviation }(\%)\end{array}$ & $\mathbf{N}$ \\
\hline 15-yates-1-bio & $8.48 \pm 0.06$ & 0.166 & $6 \%$ & 4 & 0.081 & $6 \%$ & 4 \\
\hline SRM278 & $3.41 \pm 0.02$ & 0.097 & $12 \%$ & 10 & 0.050 & $11 \%$ & 10 \\
\hline JA3 & $1.17 \pm 0.10$ & 0.049 & $8 \%$ & 31 & 0.024 & $13 \%$ & 31 \\
\hline JB2 & $0.35 \pm 0.01$ & 0.027 & $10 \%$ & 31 & 0.013 & $13 \%$ & 31 \\
\hline AGV-2 & $2.39 \pm 0.09$ & 0.077 & $7 \%$ & 31 & 0.039 & $8 \%$ & 31 \\
\hline plg AMP3.8 & $0.29 \pm 0.01$ & 0.016 & $18 \%$ & 6 & 0.008 & $12 \%$ & 6 \\
\hline \multirow[t]{2}{*}{ amp AMP3.8 } & $0.34 \pm 0.00$ & 0.023 & $12 \%$ & 18 & 0.008 & $18 \%$ & 18 \\
\hline & & \multicolumn{6}{|c|}{ Ablation time longer than $15 \mathrm{~s}$} \\
\hline Sample name & $\begin{array}{c}\text { Ref. } K \text { content } \\
\pm \text { un. }(\text { wt. } \%)\end{array}$ & $\begin{array}{l}\text { K\% predict } \\
(766.49 \mathrm{~nm})\end{array}$ & $\begin{array}{c}\text { Standard } \\
\text { deviation }(\%)\end{array}$ & $\mathbf{N}$ & \begin{tabular}{|l|} 
K\% predict \\
$(769.89 \mathrm{~nm})$
\end{tabular} & $\begin{array}{c}\text { Standard } \\
\text { deviation }(\%)\end{array}$ & $\mathbf{N}$ \\
\hline SRM278 & $3.41 \pm 0.02$ & 5.58 & $22 \%$ & 55 & 5.69 & $22 \%$ & 55 \\
\hline JA3 & $1.17 \pm 0.10$ & 1.42 & $21 \%$ & 76 & 1.42 & $21 \%$ & 76 \\
\hline JB2 & $0.35 \pm 0.01$ & 0.66 & $23 \%$ & 76 & 0.70 & $35 \%$ & 76 \\
\hline AGV-2 & $2.39 \pm 0.09$ & 2.84 & $12 \%$ & 76 & 2.82 & $11 \%$ & 76 \\
\hline plg AMP3.8 & $0.29 \pm 0.01$ & 0.18 & $18 \%$ & 8 & 0.25 & $12 \%$ & 8 \\
\hline amp AMP3.8 & $0.34 \pm 0.00$ & 0.39 & $9 \%$ & 48 & 0.25 & $19 \%$ & 48 \\
\hline
\end{tabular}


Table 5: LIBS K content analyses for samples TL18, TL19, 30-01 ( $\left(^{\mathrm{a}}: 0.5-1 \mathrm{~mm}\right.$, and ${ }^{\mathrm{b}}: 0.12-$ $0.25 \mathrm{~mm}$ size fractions), ADB, and AMP3.8 (Ref.: Reference $\mathrm{K}$ content obtained by spectrophotometry; this work; ${ }^{1}$ : Courtillot et al., 2010; ${ }^{2}$ : Ricci et al., 2013; Stdev.: standard deviation; N: number of LIBS analyses performed).

\begin{tabular}{|c|c|c|c|c|c|c|c|}
\hline Sample name & TL18 & TL19 & $30-01$ & $A D B$ & \multicolumn{3}{|c|}{ AMP3.8 } \\
\hline Analyzed crystal & plg & plg & plg & plg & plg & amp & mix phase \\
\hline Ref. $K$ content (wt.\%) & $0.351^{2}$ & $0.257^{2}$ & $0.202^{a, 1}-0.355^{b, 1}$ & 0.500 & 0.287 & 0.344 & $0.287-0.344$ \\
\hline LIBS K content (wt.\%) & 0.278 & 0.254 & 0.278 & 0.401 & 0.306 & 0.299 & 0.291 \\
\hline LIBS Stdev. & \pm 0.062 & \pm 0.090 & \pm 0.020 & \pm 0.078 & \pm 0.075 & \pm 0.033 & \pm 0.038 \\
\hline LIBS relative Stdev. (\%) & 22 & 35 & 7 & 19 & 25 & 11 & 13 \\
\hline $\mathbf{N}$ & 9 & 8 & 5 & 8 & 3 & 4 & 10 \\
\hline
\end{tabular}


Table 6: Comparison between $\mathrm{K}$ content obtained using differents techniques (EPMA, ICPOES, Spectrophotometry and LIBS).

\begin{tabular}{|c|c|c|c|c|c|}
\hline \multirow{2}{*}{ Sample name } & \multirow{2}{*}{ Mineral phases } & \multicolumn{4}{|c|}{ K content determination using several techniques: } \\
\hline & & EPMA & ICP-OES & Spectrophotometry & LIBS \\
\hline $30-01$ & Plagioclase & - & - & $0.202 \pm 0.002$ & $0.28 \pm 0.02$ \\
\hline $\mathrm{ADB}$ & Plagioclase & - & - & $0.500 \pm 0.005$ & $0.40 \pm 0.08$ \\
\hline AMP3.8 & $\begin{array}{l}\text { Amphibole } \\
\text { Plagioclase }\end{array}$ & $\begin{array}{l}0.34 \pm 0.04 \\
0.05 \pm 0.02\end{array}$ & $\begin{array}{c}0.35 \pm 0.09 \\
-\end{array}$ & $\begin{array}{l}0.344 \pm 0.002 \\
0.287 \pm 0.004\end{array}$ & $\begin{array}{l}0.30 \pm 0.03 \\
0.31 \pm 0.08\end{array}$ \\
\hline
\end{tabular}


Table 7: Comparison between KArMars and reference ages (this work; ${ }^{1}$ : Courtillot et al., 2010; ${ }^{2}$ : Ricci et al., 2013). The relative accuracy of KArMars results is given in column A\% (in \%).*: mean value calculated from plagioclase and amphibole ages.

\begin{tabular}{|c|c|c|c|c|}
\hline $\begin{array}{c}\text { Sample } \\
\text { name }\end{array}$ & $\begin{array}{c}\text { Analyzed } \\
\text { mineral }\end{array}$ & $\begin{array}{c}\text { Reference K-Ar age } \\
\pm \text { un (Ma) }\end{array}$ & $\begin{array}{c}\text { KArMars age } \pm \\
\text { un (Ma) }\end{array}$ & A\% \\
\hline \multirow{3}{*}{ AMP3.8 } & plagioclase & $2052 \pm 29$ & $2218 \pm 135$ & $8 \%$ \\
\cline { 2 - 5 } & amphibole & $2649 \pm 38$ & $2913 \pm 292$ & $10 \%$ \\
\cline { 2 - 5 } & mix phases & $2351 \pm 300^{*}$ & $2585 \pm 138$ & $10 \%$ \\
\hline ADB & plagioclase & $1447 \pm 21$ & $1382 \pm 46$ & $6 \%$ \\
\hline 30-01 & plagioclase & $369 \pm 5^{1}$ & $362 \pm 16$ & $5 \%$ \\
\hline TL-18 & plagioclase & $381 \pm 5^{2}$ & $358 \pm 20$ & $5 \%$ \\
\hline TL-19 & plagioclase & $378 \pm 5^{2}$ & $351 \pm 33$ & $5 \%$ \\
\hline TO-35 & plagioclase & $374 \pm 5^{2}$ & $406 \pm 210$ & $9 \%$ \\
\hline
\end{tabular}

